Electronic Supplementary Information

\title{
Activation of Dioxygen by a Mononuclear Nonheme Iron Complex: Sequential Peroxo, Oxo, and Hydroxo Intermediates
}

Jesse B. Gordon, ${ }^{a}$ Avery C. Vilbert, ${ }^{b}$ Ida M. DiMucci, ${ }^{b}$ Samantha N. MacMillan, ${ }^{b}$ Kyle M. Lancaster, ${ }^{b *}$ Pierre Moënne-Loccoz, ${ }^{c *}$ and David P. Goldberg ${ }^{a *}$

${ }^{a}$ Department of Chemistry, The Johns Hopkins University, 3400 N. Charles Street, Baltimore, MD 21218, USA

${ }^{b}$ Department of Chemistry and Chemical Biology, Baker Laboratory, Cornell University, Ithaca, NY 14853

${ }^{c}$ Department of Chemical Physiology and Biochemistry, Oregon Health \& Science University, Portland, Oregon 97239, USA 


\section{Table of Contents}

UV-vis spectrum of $\mathbf{1}$

Mössbauer spectrum of $\mathbf{1}$

Cyclic voltammetry data for $\mathbf{1}$

UV-vis and Mössbauer data for $\mathbf{1}^{\mathbf{0 x}}$

S7 - 10

$\mathrm{UV}$-vis data for formation of 2 at $-105{ }^{\circ} \mathrm{C}$

S11

$5 \mathrm{~K}$ Mössbauer data for 2

S12 - 13

Photobleaching of $\mathbf{2}$

EXAFS data and fits for $\mathbf{1}-\mathbf{4}$

S15 - 18

UV-vis data for attempted $\mathrm{H}_{2} \mathrm{O}_{2}$ release from 2

S19

Data for UV photodecay of $\mathbf{3}$

S20 - 21

Plot of $\delta$ versus UV-vis $\lambda_{\max }$ for $d-d$ bands in $\mathrm{Fe}^{\mathrm{IV}}(\mathrm{O})$ complexes

S22

UV-vis and Mössbauer spectra of thermal decay of $\mathbf{2}$ to $\mathbf{3}$

S23 - 24

EPR quantitation data

S25 - 30

UV-vis and Mössbauer spectra for the formation of 4

S31 - 34

Summary of all Mössbauer data

S35

DFT geometry scan for $\mathbf{3}$

S36

Table of bond metrics for DFT models

S37

Coordinates from DFT geometry optimizations

$\mathrm{S38}-43$

References

S44 


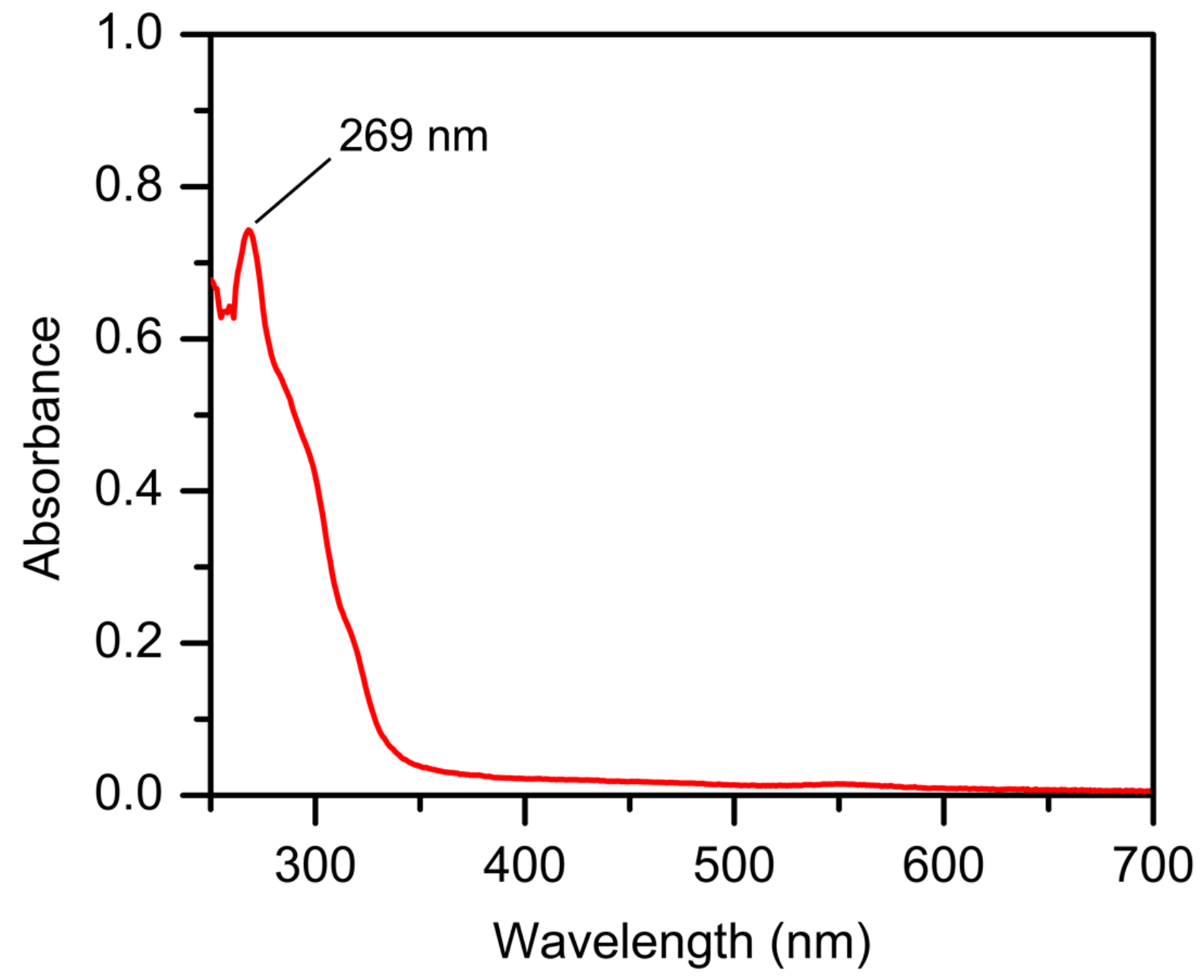

Figure S1. UV-vis spectrum of 1 in $2-\operatorname{MeTHF}(0.2 \mathrm{mM})$ at $-135^{\circ} \mathrm{C}$. 


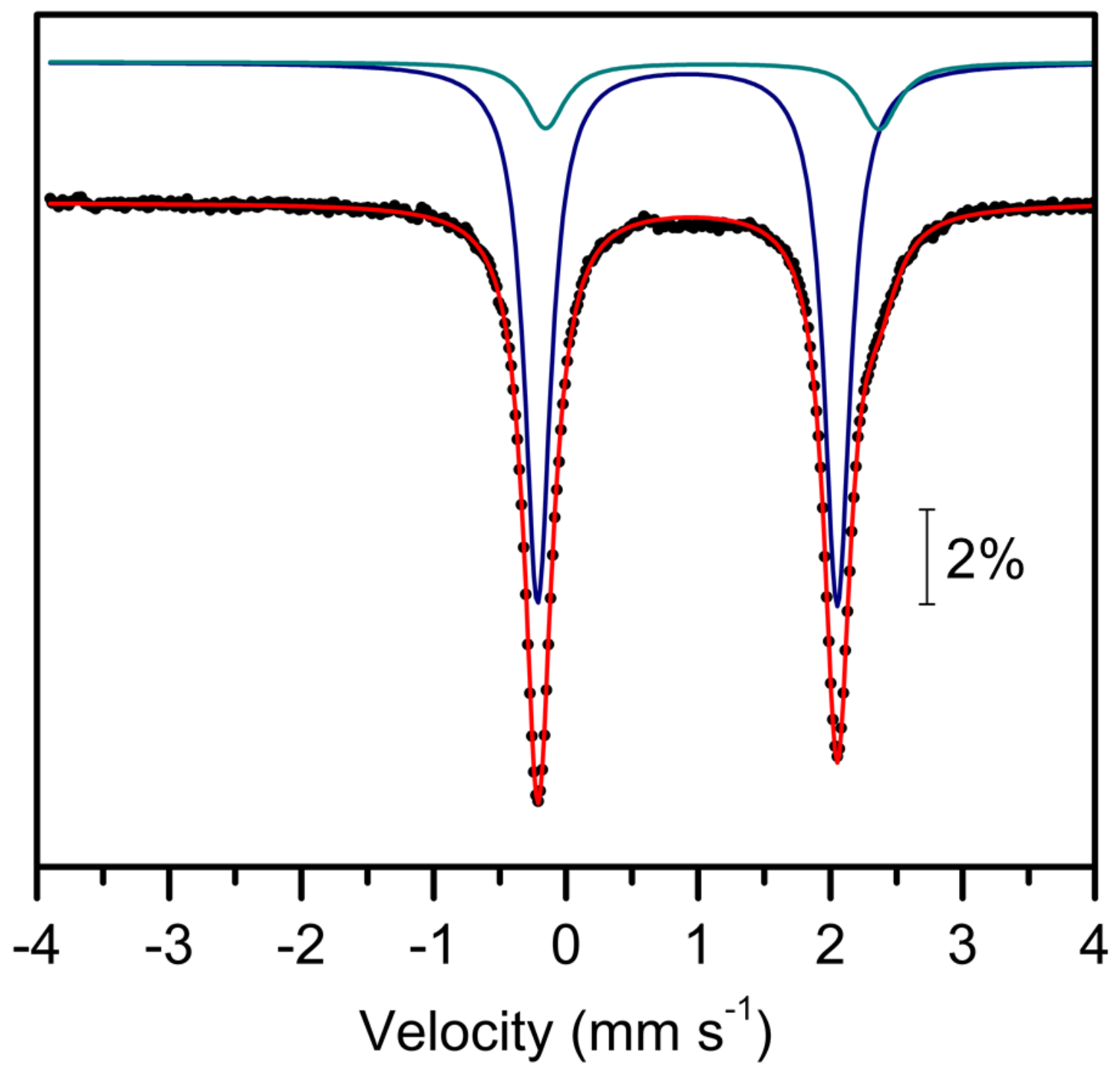

Figure S2. Zero-field ${ }^{57} \mathrm{Fe}$ Mössbauer spectrum of $\mathbf{1}$ (natural abundance) as a solid dispersed in boron nitride at $5 \mathrm{~K}$. Overall fit shown as a red line. Fits for sub-spectra shown as blue and green lines. The major quadrupole doublet exhibits parameters with $\delta=0.92 \mathrm{~mm} \mathrm{~s}^{-1},\left|\Delta \mathrm{E}_{\mathrm{Q}}\right|=2.27 \mathrm{~mm}$ $\mathrm{s}^{-1}$, and $\Gamma_{\mathrm{L}, \mathrm{R}}=0.24 \mathrm{~mm} \mathrm{~s}^{-1}$ that makes up $85 \%$ of the total fit. A second quadrupole doublet with parameters $\delta=1.11 \mathrm{~mm} \mathrm{~s}^{-1},\left|\Delta \mathrm{E}_{\mathrm{Q}}\right|=2.52 \mathrm{~mm} \mathrm{~s}^{-1}$, and $\Gamma_{\mathrm{L}, \mathrm{R}}=0.35 \mathrm{~mm} \mathrm{~s}^{-1}$ makes up $15 \%$ of the total fit, and is assigned to a second conformer of $\mathbf{1}$. 


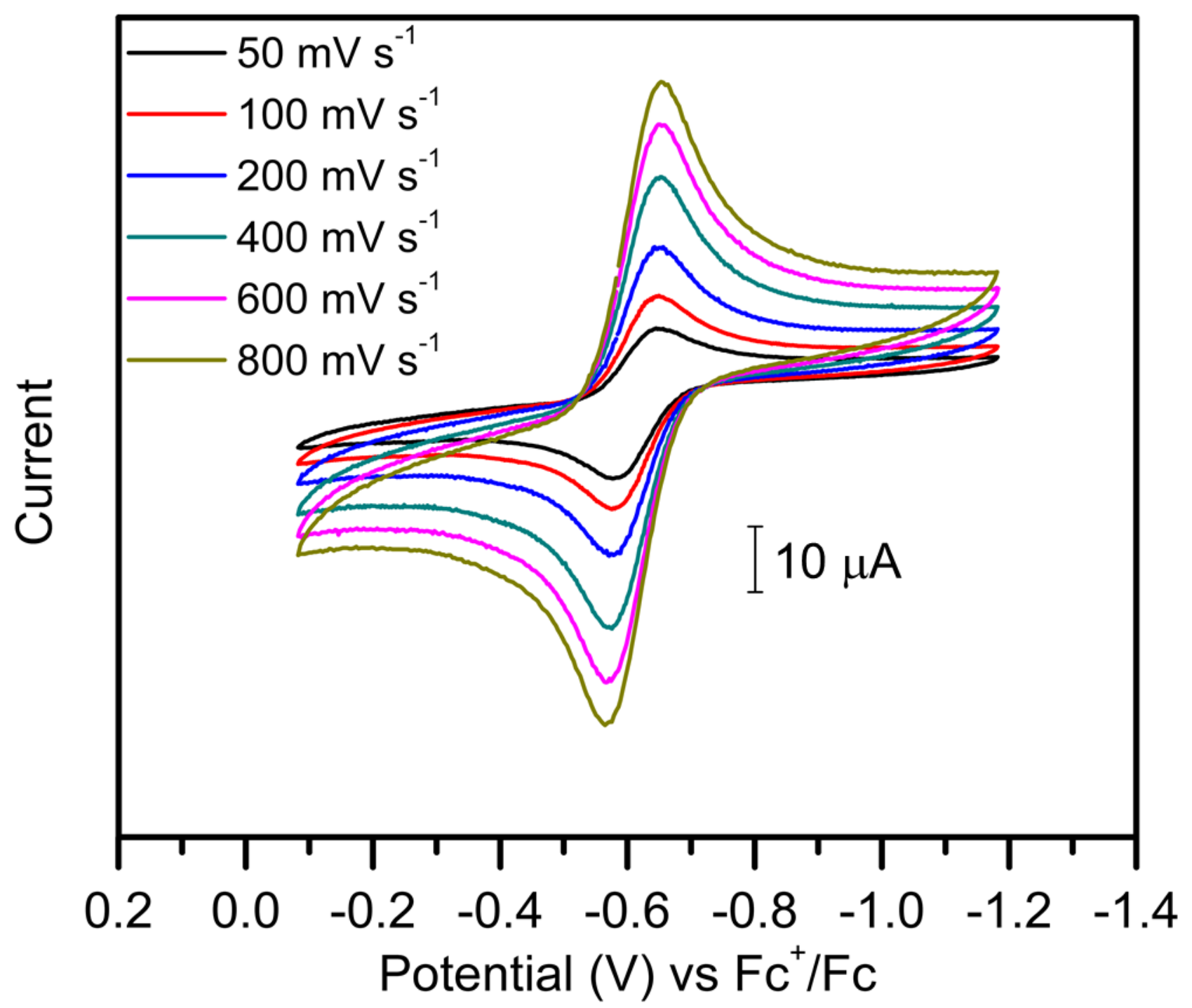

Figure S3. Cyclic voltammograms showing the scan rate dependence of $\left[\mathrm{FeS}_{2}\right]^{+} /\left[\mathrm{FeS}_{2}\right]^{0}$ couple for $1(5 \mathrm{mM})$ in acetonitrile at $23{ }^{\circ} \mathrm{C}$, using $0.3 \mathrm{M}^{n} \mathrm{Bu}_{4} \mathrm{NPF}_{6}$ as electrolyte. Working electrode: platinum; Counter electrode: Pt wire; Reference electrode: Ag wire. Scan rate varied from 50 $800 \mathrm{mV} \mathrm{s}^{-1}$. 


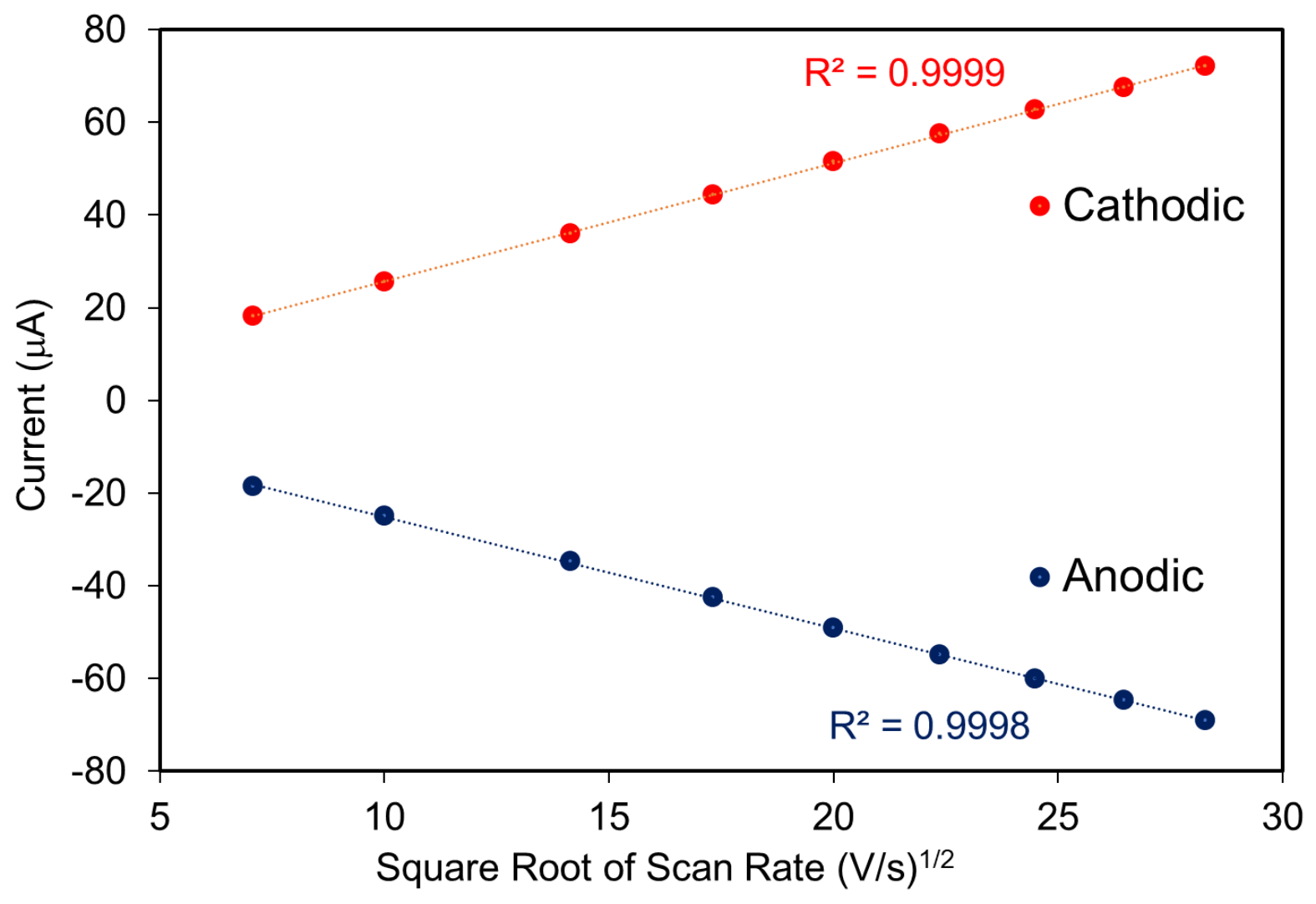

Figure S4. Plots of current versus square root of the scan rate for the cyclic voltammetry data shown in Figure S3. 


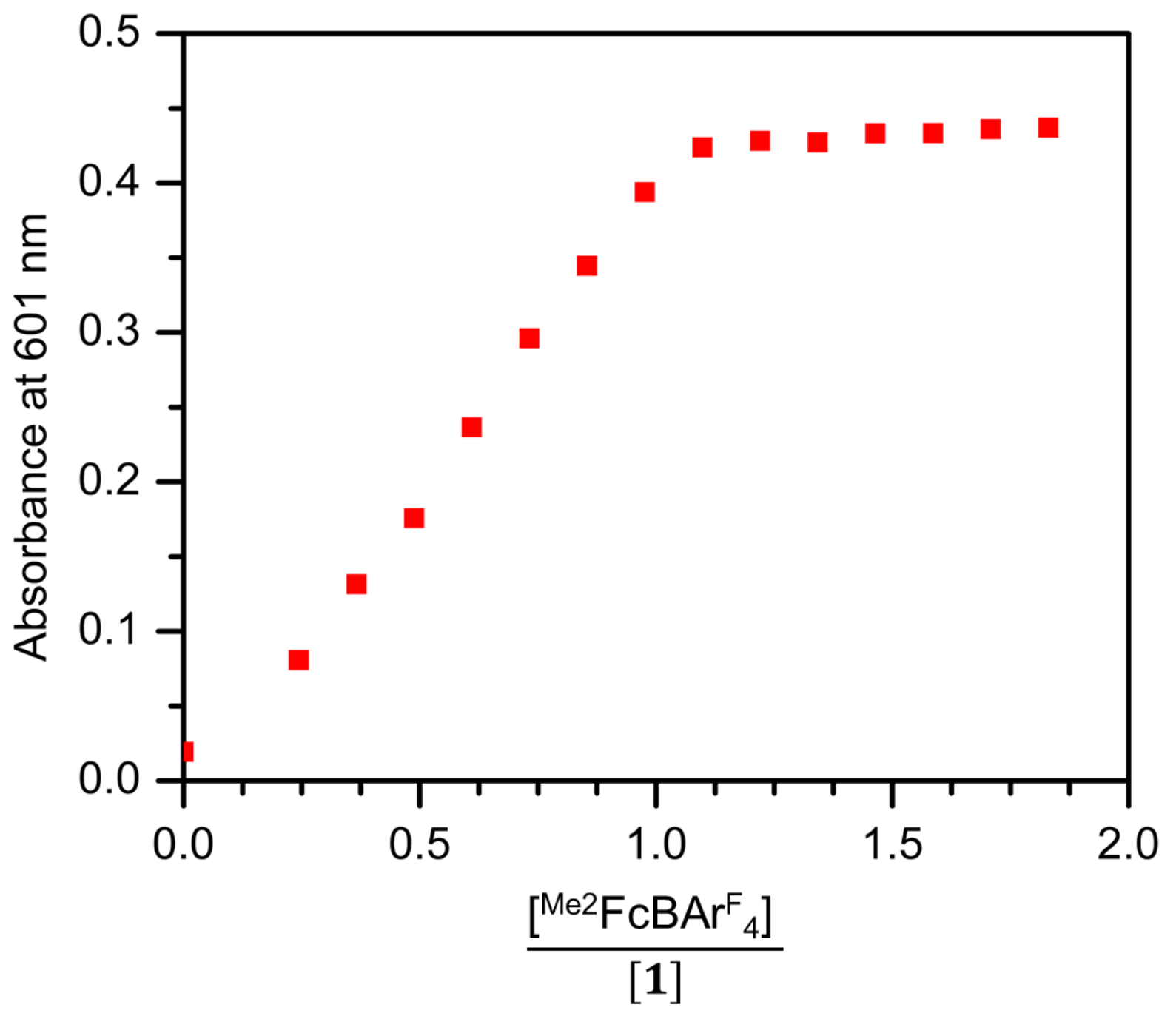

Figure S5. Titration curve for the reaction of 1 with ${ }^{\mathrm{Me} 2} \mathrm{FcBAr}^{\mathrm{F}}{ }_{4}$ in $2-\mathrm{MeTHF}$ at $-80{ }^{\circ} \mathrm{C}$. The plot shows absorbance at $601 \mathrm{~nm}$, a peak corresponding to $\mathbf{1}^{\mathbf{0 x}}$, versus equiv of ${ }^{\mathrm{Me} 2} \mathrm{FcBAr}^{\mathrm{F}}$. Oxidation is complete with 1.04 equiv of oxidant, consistent with a 1:1 stoichiometry. 


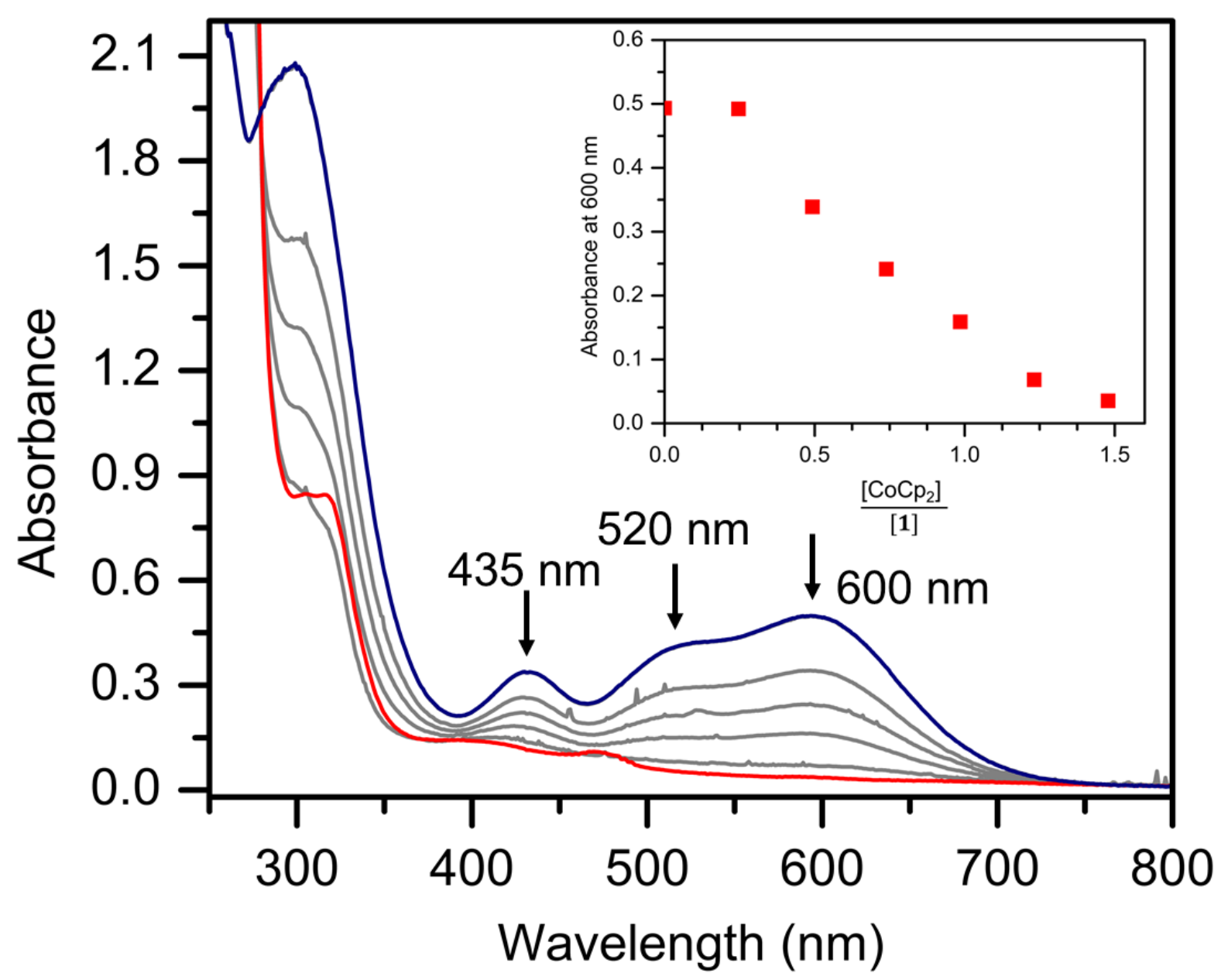

Figure S6. UV-vis spectral changes for the titration of $\mathbf{1}^{\mathbf{0 x}}(0.22 \mathrm{mM})$ with $\mathrm{Co}^{\mathrm{II}} \mathrm{Cp}_{2}(0-1.5$ equiv $)$ in 2-MeTHF at $-80{ }^{\circ} \mathrm{C}$. Inset: Plot of absorbance at $600 \mathrm{~nm}$, a peak corresponding to $\mathbf{1}^{\mathbf{o x}}$ versus equiv of $\mathrm{CoCp}_{2}$. A slight excess of reductant is required because of the excess oxidant added to generate $\mathbf{1}^{\mathbf{0 x}}$. 


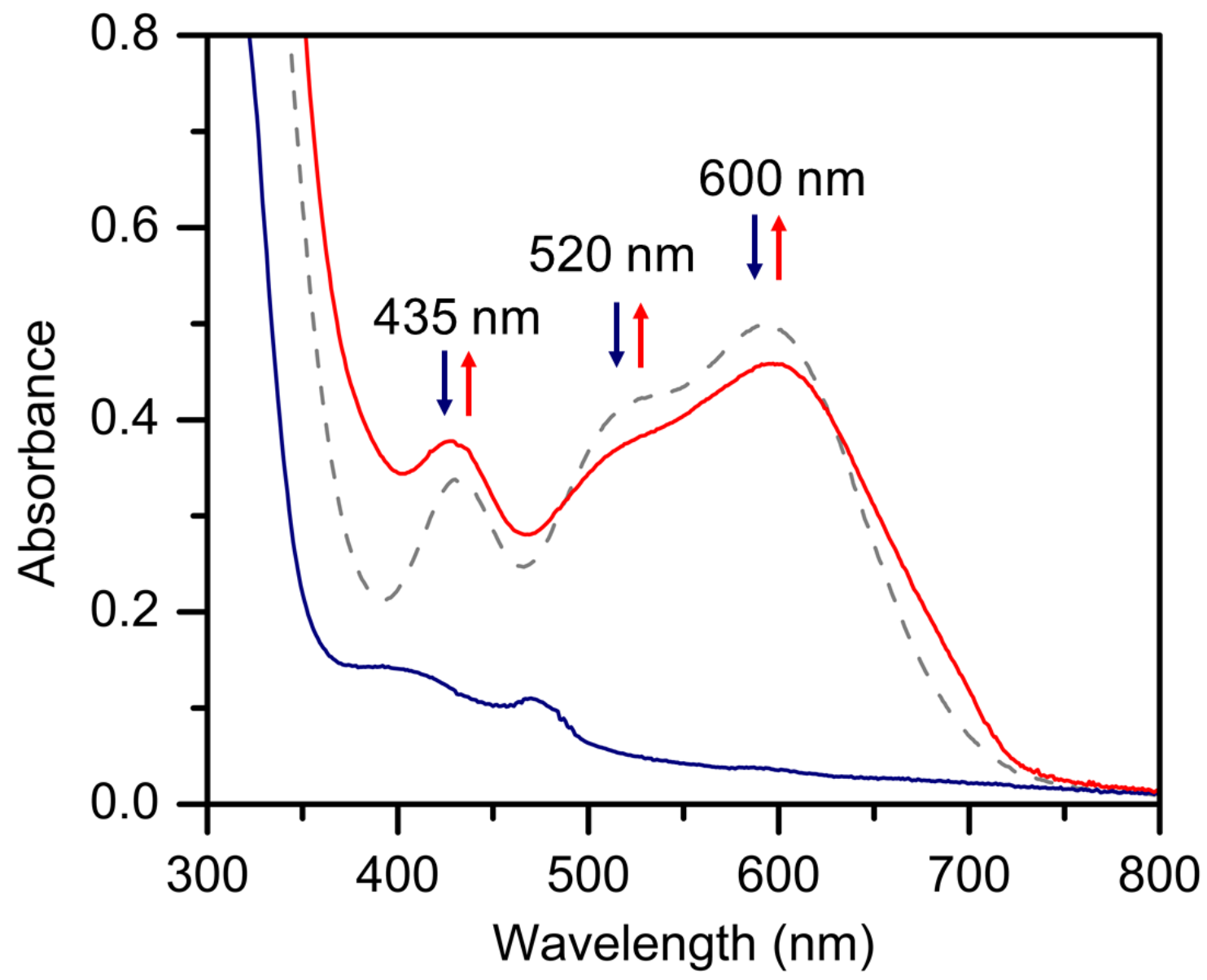

Figure S7. UV-vis spectra showing reduction of $\mathbf{1}^{\text {ox }}(0.22 \mathrm{mM}$, grey dashed line) by adding 1.5 equiv of $\mathrm{Co}^{\mathrm{II}} \mathrm{Cp}_{2}$ to give reduced $\mathbf{1}$ (blue line) followed by re-oxidation with excess ${ }^{\mathrm{Me} 2} \mathrm{FcBAr}^{\mathrm{F}}{ }_{4}$ to give $\mathbf{1}^{\mathbf{0 x}}$ (red line) at $-80^{\circ} \mathrm{C}$. 


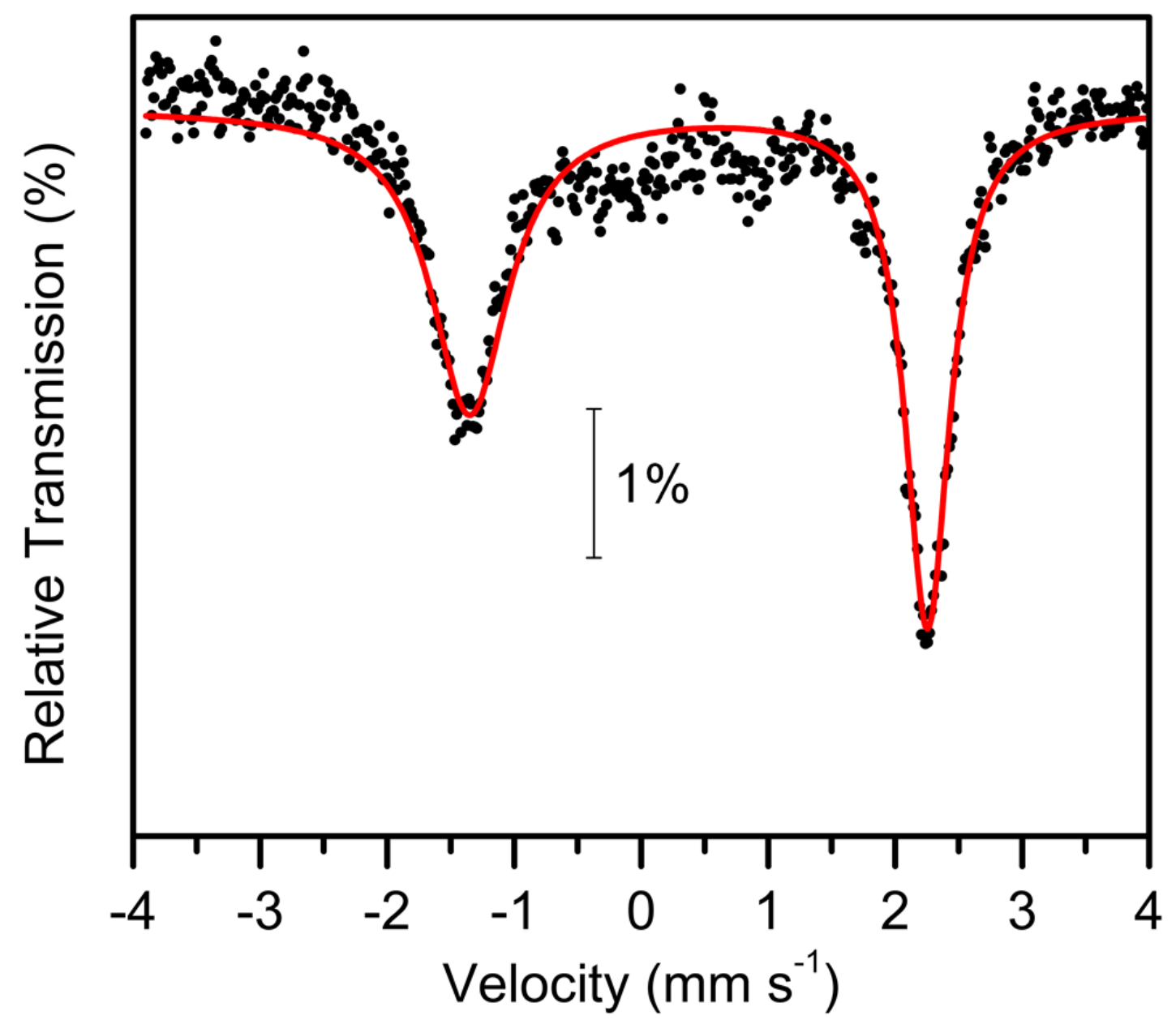

Figure S8. Zero-field ${ }^{57} \mathrm{Fe}$ Mössbauer spectrum of $\mathbf{1}^{\mathbf{0 x}}\left({ }^{\mathbf{5 7}} \mathbf{F e}\right)$ at $80 \mathrm{~K}$ in 2 -MeTHF. The fit for the major quadrupole doublet (red line) gives parameters $\delta=0.45 \mathrm{~mm} \mathrm{~s}^{-1},\left|\Delta \mathrm{E}_{\mathrm{Q}}\right|=3.6 \mathrm{~mm} \mathrm{~s}^{-1}, \Gamma_{\mathrm{L}}=$ $0.74 \mathrm{~mm} \mathrm{~s}^{-1}$, and $\Gamma_{\mathrm{R}}=0.43 \mathrm{~mm} \mathrm{~s}^{-1}$. The asymmetric line broadening may be attributed to spin relaxation effects, which are common for ferric complexes. ${ }^{1}$ 


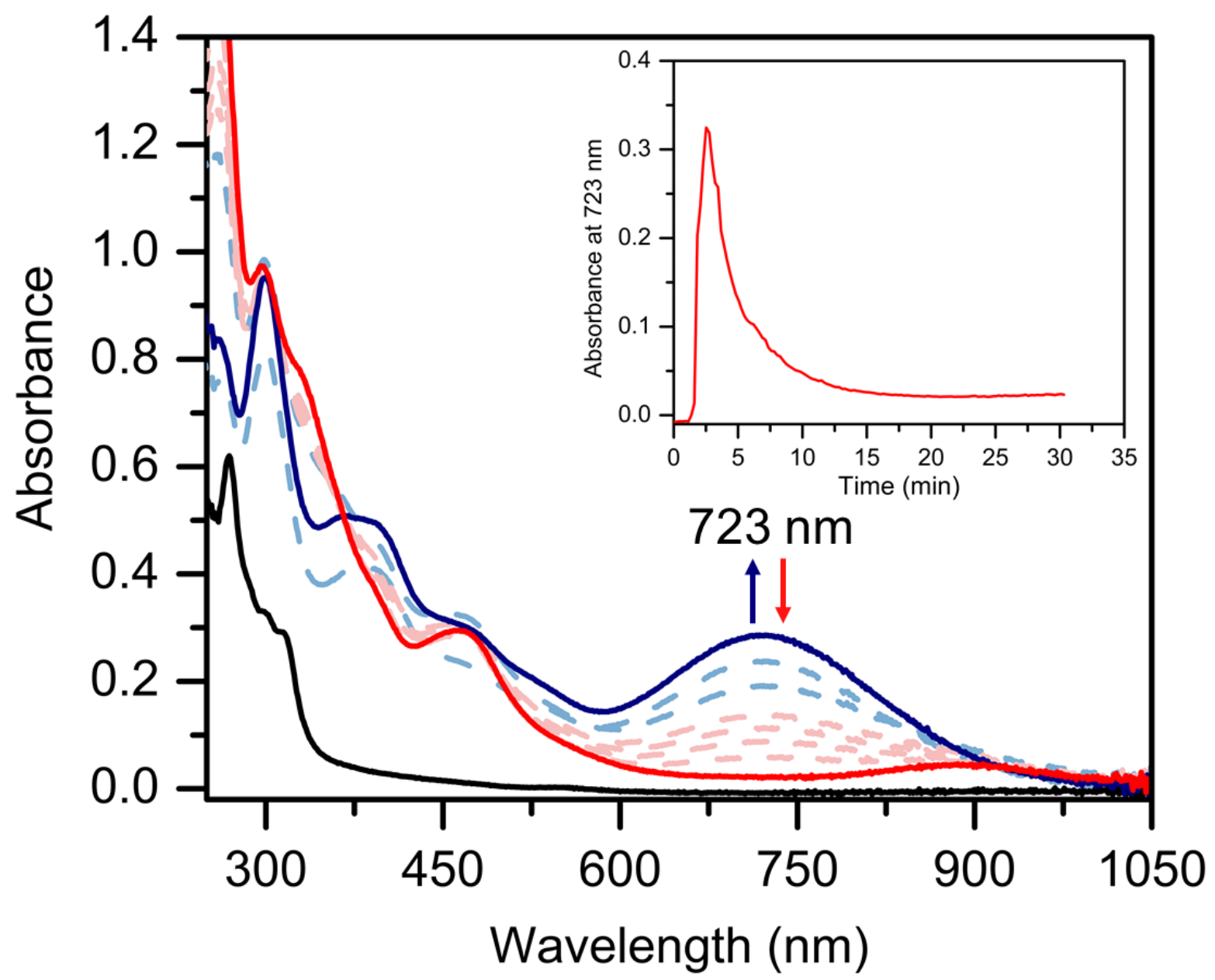

Figure S9. UV-vis spectral changes for the addition of excess $\mathrm{O}_{2}$ to $\mathbf{1}(0.1 \mathrm{mM})$ in THF at -105 ${ }^{\circ} \mathrm{C}$. Black line corresponds to $\mathbf{1}$. Blue line corresponds to maximally formed $\mathbf{2}$. Red line corresponds to final scan following decay of $\mathbf{2}$. Scans prior to maximal formation of $\mathbf{2}$ and before full decay shown as blue and red dashed lines, respectively. Inset: Plot of absorbance at $723 \mathrm{~nm}$ versus time, showing the rate of formation and decay of $\mathbf{2}$ at $-105{ }^{\circ} \mathrm{C}$. 


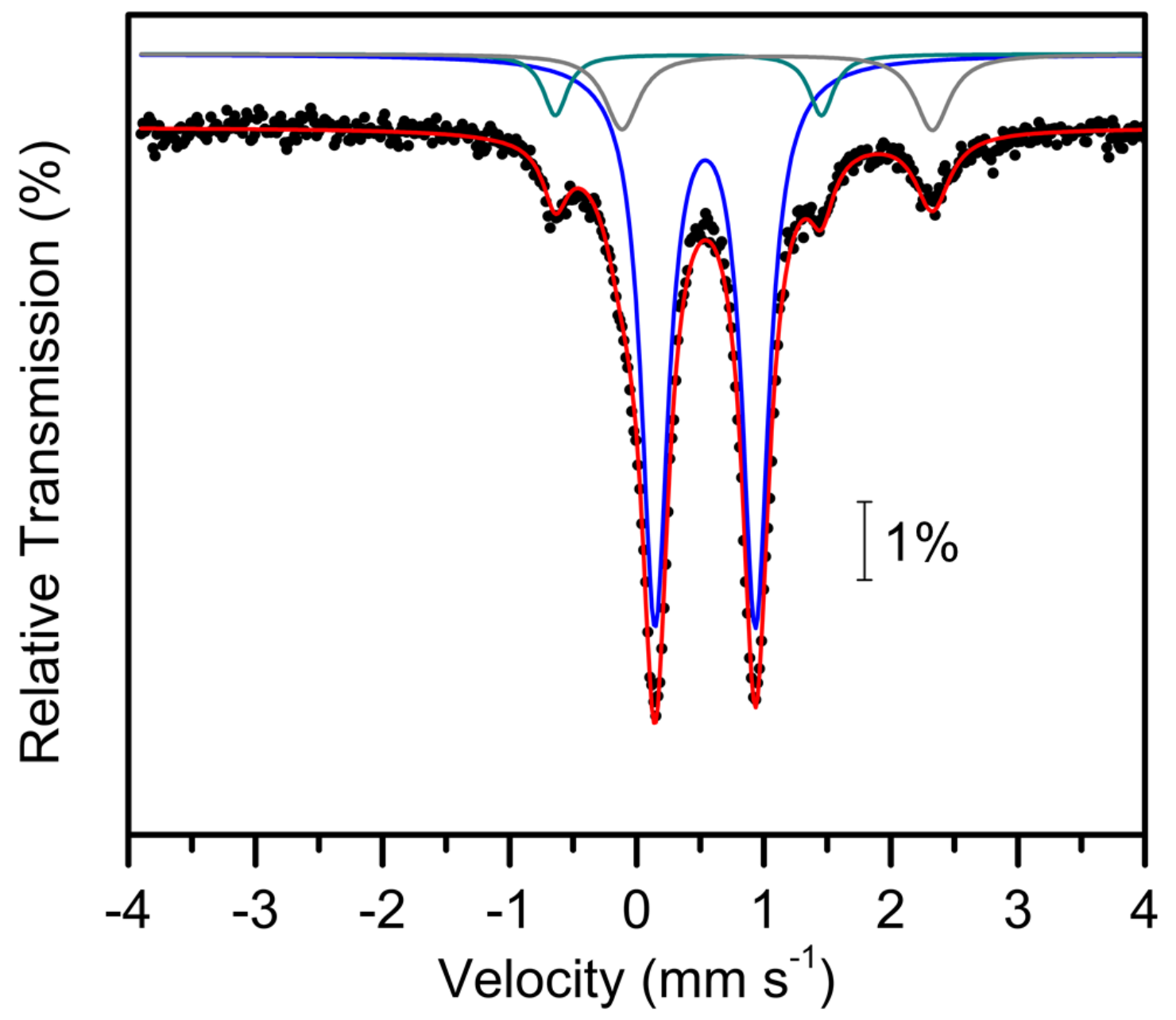

Figure S10. Zero-field ${ }^{57} \mathrm{Fe}$ Mössbauer spectrum of $2\left({ }^{57} \mathbf{F e}\right)$ at $5 \mathrm{~K}$ in 2-MeTHF. Overall fit shown as a red line. Fits for sub-spectra shown as blue, green, and grey lines. The fit for the major quadrupole doublet (blue line) corresponding to 2 gives parameters $\delta=0.54 \mathrm{~mm} \mathrm{~s}^{-1},\left|\Delta \mathrm{E}_{\mathrm{Q}}\right|=0.79$ $\mathrm{mm} \mathrm{s}^{-1}$, and $\Gamma_{\mathrm{L}, \mathrm{R}}=0.26 \mathrm{~mm} \mathrm{~s}^{-1}$ and makes up $81 \%$ of the total fit. A minor quadrupole doublet (grey line) corresponding to $11 \%$ of the fit gives parameters $\delta=1.11 \mathrm{~mm} \mathrm{~s}^{-1},\left|\Delta \mathrm{E}_{\mathrm{Q}}\right|=2.44 \mathrm{~mm} \mathrm{~s}^{-}$ ${ }^{1}$, and $\Gamma_{\mathrm{L}, \mathrm{R}}=0.33 \mathrm{~mm} \mathrm{~s}^{-1}$. Another minor quadrupole doublet (green line) corresponding to $8 \%$ of the fit gives parameters $\delta=0.41 \mathrm{~mm} \mathrm{~s}^{-1},\left|\Delta \mathrm{E}_{\mathrm{Q}}\right|=2.1 \mathrm{~mm} \mathrm{~s}^{-1}$, and $\Gamma_{\mathrm{L}, \mathrm{R}}=0.23 \mathrm{~mm} \mathrm{~s}^{-1}$ 


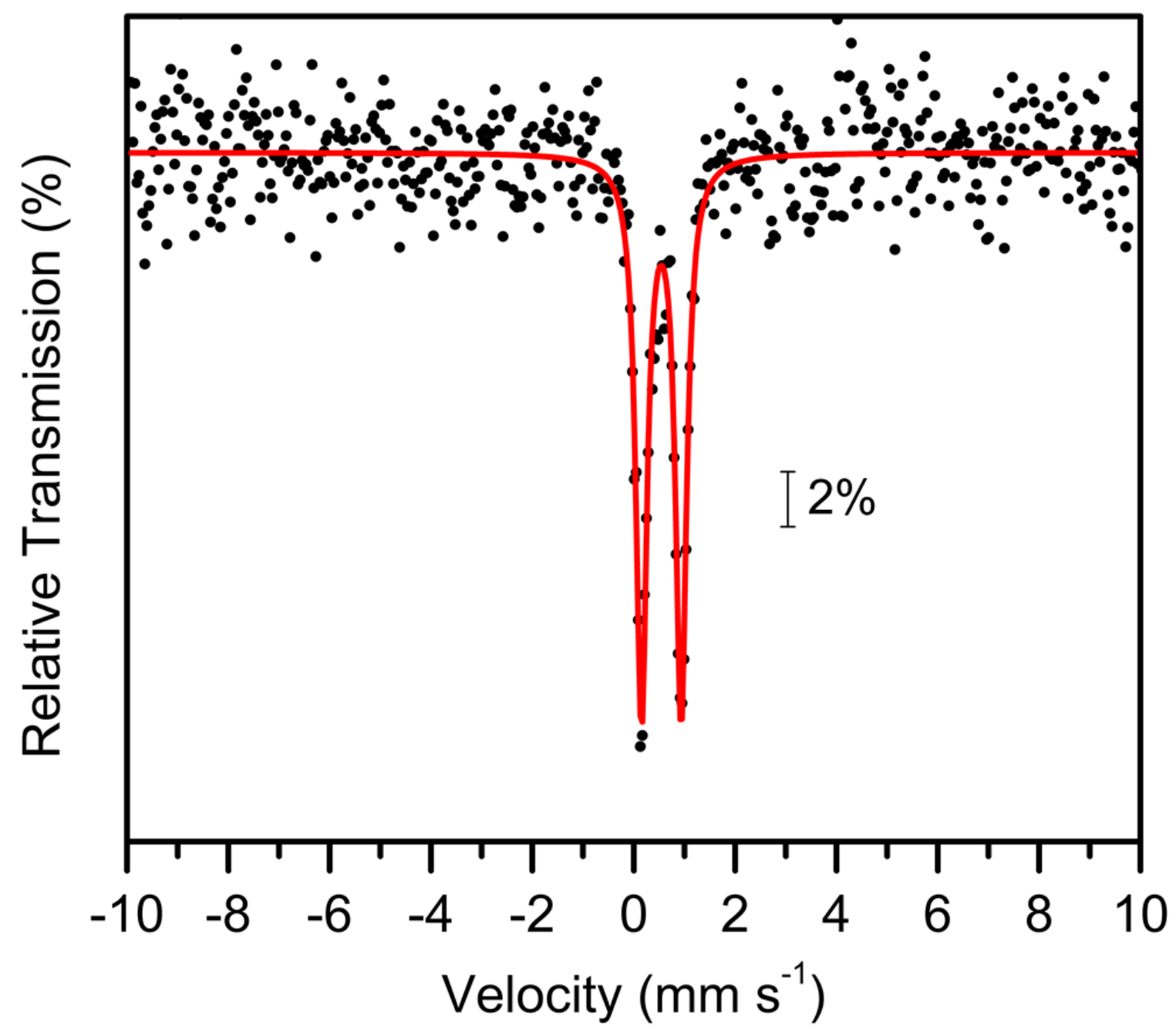

Figure S11. ${ }^{57} \mathrm{Fe}$ Mössbauer spectrum of $2\left({ }^{57} \mathbf{F e}\right)$ at $5 \mathrm{~K}$ recorded in a parallel field of $50 \mathrm{mT}$ in 2MeTHF. Overall fit shown as a red line, giving fit parameters $\delta=0.54 \mathrm{~mm} \mathrm{~s}^{-1},\left|\Delta \mathrm{E}_{\mathrm{Q}}\right|=0.78 \mathrm{~mm}$ $\mathrm{s}^{-1}$, and $\Gamma_{\mathrm{L}, \mathrm{R}}=0.26 \mathrm{~mm} \mathrm{~s}^{-1}$. 


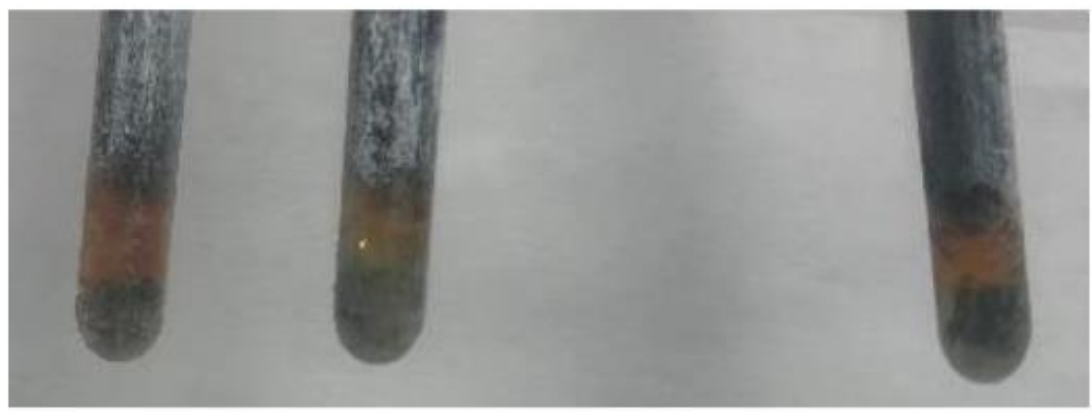

Figure S12. Photobleaching of RR samples of green 2 after $2 \times 30$ s exposure to the 407-nm laser beam ( $5 \mathrm{~mW}$ defocused on a $5 \times 0.2 \mathrm{~mm}$ sample area). 

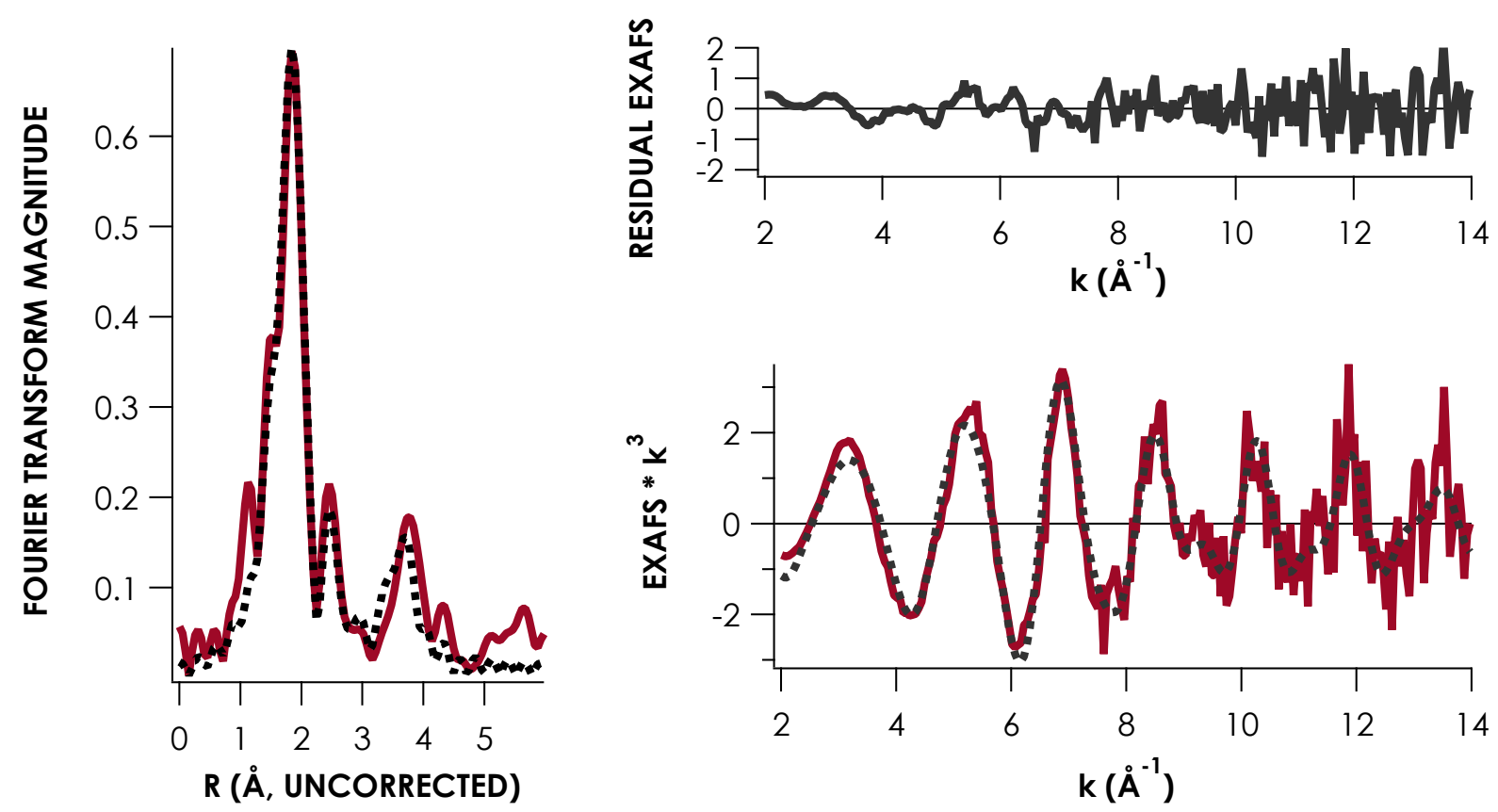

Figure S13. Fe K-edge EXAFS of $\mathrm{Fe}^{\mathrm{II}}\left(\mathrm{Me}_{3} \mathrm{TACN}\right)\left(\mathrm{S}_{2} \mathrm{SiMe}_{2}\right)$ obtained at $10 \mathrm{~K}$. Experimental data is plotted as a solid red trace and fits are shown as dotted lines. EXAFS data were simulated using EXAFS pack. Data were fit to the unsmoothed raw data and simulated over the range $\mathrm{k}=$ $2-14 \AA^{-1}$.

Table S1. EXAFS simulations for 1. EXAFS data were fit with EXAFSPAK using paths calculated by FEFF7. Distance and Debye-Waller factors were allowed to float while, coordination numbers were held constant. Goodness of fit is determined by $\mathrm{F}$, defined as $\left[\left(\sum_{i}^{n}\left[k_{i}^{3}\left(E X A F S_{o b s}-\right.\right.\right.\right.$ $\left.\left.\left.\left.\operatorname{EXAFS}_{\text {calc }}\right)_{i}\right]\right)^{2} / n\right]^{1 / 2}$.

\begin{tabular}{|c|c|c|c|c|c|c|c|c|}
\hline Fit & Path & $\mathbf{C N}$ & $\mathbf{R}(\AA)$ & \pm & $\sigma^{2}$ & \pm & $\mathrm{E}_{0}(\mathrm{eV})$ & $\mathbf{F}$ factor \\
\hline 1 & Fe-N & 3 & 2.291 & 0.005 & 0.0036 & 0.0003 & -7.27 & 54.57 \\
\hline 2 & $\mathrm{Fe}-\mathrm{S}$ & 2 & 2.375 & 0.006 & 0.0061 & 0.0003 & -26.25 & 56.17 \\
\hline \multirow[t]{2}{*}{3} & $\mathrm{Fe}-\mathrm{S}$ & 2 & 2.46 & 0.02 & 0.017 & 0.002 & -11.45 & 49.73 \\
\hline & $\mathrm{Fe}-\mathrm{N}$ & 3 & 2.277 & 0.005 & 0.0044 & 0.0004 & & \\
\hline \multirow[t]{3}{*}{4} & $\mathrm{Fe}-\mathrm{S}$ & 2 & 2.50 & 0.02 & 0.020 & 0.002 & -9.88 & 47.45 \\
\hline & $\mathrm{Fe}-\mathrm{N}$ & 3 & 2.280 & 0.005 & 0.0041 & 0.0003 & & \\
\hline & $\mathrm{Fe}-\mathrm{Si}$ & 1 & 2.95 & 0.02 & 0.009 & 0.002 & & \\
\hline \multirow[t]{4}{*}{5} & $\mathrm{Fe}-\mathrm{S}$ & 2 & 2.49 & 0.02 & 0.020 & 0.002 & -9.97 & 46.93 \\
\hline & $\mathrm{Fe}-\mathrm{N}$ & 3 & 2.279 & 0.005 & 0.0042 & 0.0003 & & \\
\hline & $\mathrm{Fe}-\mathrm{Si}$ & 1 & 2.96 & 0.02 & 0.010 & 0.002 & & \\
\hline & $\mathrm{Fe}-\mathrm{S}-\mathrm{Si}(\mathrm{MS})$ & 4 & 3.67 & 0.03 & 0.001 & 0.002 & & \\
\hline \multirow[t]{5}{*}{6} & $\mathrm{Fe}-\mathrm{S}$ & 2 & 2.50 & 0.02 & 0.019 & 0.002 & -9.63 & 43.56 \\
\hline & $\mathrm{Fe}-\mathrm{N}$ & 3 & 2.280 & 0.004 & 0.0042 & 0.0003 & & \\
\hline & $\mathrm{Fe}-\mathrm{Si}$ & 1 & 2.96 & 0.02 & 0.010 & 0.002 & & \\
\hline & $\mathrm{Fe}-\mathrm{S}-\mathrm{Si}(\mathrm{MS})$ & 4 & 3.65 & 0.02 & 0.0005 & 0.001 & & \\
\hline & $\mathrm{Fe}-\mathrm{C}$ & 3 & 4.095 & 0.009 & 0.0015 & 0.0007 & & \\
\hline
\end{tabular}


Table S2. EXAFS simulations for 2. EXAFS data were fit with EXAFSPAK using paths calculated by FEFF7. Distance and Debye-Waller factors were allowed to float while, coordination numbers were held constant. Goodness of fit is determined by $\mathrm{F}$, defined as $\left[\left(\sum_{i}^{n}\left[k_{i}^{3}\left(E X A F S_{o b s}-\right.\right.\right.\right.$ EXAFS $\left.\left.\left.\left._{\text {calc }}\right)_{i}\right]\right)^{2} / n\right]^{1 / 2}$.

\begin{tabular}{|c|c|c|c|c|c|c|c|c|}
\hline Fit & Path & $\mathbf{C N}$ & $\mathbf{R}(\AA)$ & \pm & $\sigma^{2}$ & \pm & $\mathrm{E}_{0}(\mathrm{eV})$ & $\mathbf{F}$ factor \\
\hline 1 & $\mathrm{Fe}-\mathrm{S}$ & 2 & 2.75 & 0.01 & 0.0007 & 0.0003 & -68.44 & 66.95 \\
\hline 2 & $\mathrm{Fe}-\mathrm{S}$ & 3 & 2.76 & 0.01 & 0.0026 & 0.0003 & -64.72 & 70.52 \\
\hline 3 & $\mathrm{Fe}-\mathrm{N}$ & 2 & 2.47 & 0.01 & -0.0023 & 0.0004 & -12.62 & 73.23 \\
\hline 4 & $\mathrm{Fe}-\mathrm{N}$ & 3 & 2.47 & 0.01 & -0.0003 & 0.0004 & -15.93 & 76.24 \\
\hline \multirow[t]{2}{*}{5} & $\mathrm{Fe}-\mathrm{N}$ & 3 & 2.24 & 0.01 & 0.0107 & 0.006 & -13.61 & 65.22 \\
\hline & $\mathrm{Fe}-\mathrm{S}$ & 2 & 2.640 & 0.003 & 0.0025 & 0.0004 & & \\
\hline \multirow[t]{3}{*}{6} & Fe-N & 3 & 2.15 & 0.01 & 0.006 & 0.001 & 0.31 & 65.08 \\
\hline & $\mathrm{Fe}-\mathrm{S}$ & 2 & 2.659 & 0.005 & 0.0032 & 0.0004 & & \\
\hline & $\mathrm{Fe}-\mathrm{O}$ & 1 & 1.92 & 0.01 & 0.002 & 0.001 & & \\
\hline \multirow[t]{4}{*}{7} & $\mathrm{Fe}-\mathrm{N}$ & 3 & 2.15 & 0.01 & 0.007 & 0.001 & 0.25 & 55.87 \\
\hline & $\mathrm{Fe}-\mathrm{S}$ & 2 & 2.658 & 0.004 & 0.0030 & 0.0004 & & \\
\hline & $\mathrm{Fe}-\mathrm{O}$ & 1 & 1.92 & 0.01 & 0.0027 & 0.0009 & & \\
\hline & $\mathrm{Fe}-\mathrm{Fe}$ & 1 & 4.78 & 0.01 & -0.0003 & 0.0007 & & \\
\hline \multirow[t]{5}{*}{8} & $\mathrm{Fe}-\mathrm{N}$ & 3 & 2.159 & 0.008 & 0.0062 & 0.0008 & 1.79 & 47.32 \\
\hline & $\mathrm{Fe}-\mathrm{S}$ & 2 & 2.666 & 0.004 & 0.0031 & 0.0003 & & \\
\hline & $\mathrm{Fe}-\mathrm{O}$ & 1 & 1.918 & 0.009 & 0.0023 & 0.0007 & & \\
\hline & $\mathrm{Fe}-\mathrm{Fe}$ & 1 & 4.374 & 0.008 & -0.0007 & 0.0007 & & \\
\hline & $\mathrm{Fe}-\mathrm{O}-\mathrm{Fe}(\mathrm{MS})$ & 2 & 4.735 & 0.006 & 0.00006 & 0.0006 & & \\
\hline \multirow[t]{6}{*}{9} & $\mathrm{Fe}-\mathrm{N}$ & 3 & 2.142 & 0.007 & 0.0058 & 0.0007 & 0.58 & 41.65 \\
\hline & $\mathrm{Fe}-\mathrm{S}$ & 2 & 2.675 & 0.004 & 0.0035 & 0.0005 & & \\
\hline & $\mathrm{Fe}-\mathrm{O}$ & 1 & 1.905 & 0.007 & 0.0012 & 0.0006 & & \\
\hline & $\mathrm{Fe}-\mathrm{Fe}$ & 1 & 4.651 & 0.007 & -0.0053 & 0.0005 & & \\
\hline & $\mathrm{Fe}-\mathrm{O}-\mathrm{Fe}(\mathrm{MS})$ & 2 & 4.732 & 0.007 & -0.0034 & 0.0005 & & \\
\hline & $\mathrm{Fe}-\mathrm{Si}$ & 1 & 2.967 & 0.009 & 0.001 & 0.001 & & \\
\hline \multirow[t]{7}{*}{10} & $\mathrm{Fe}-\mathrm{N}$ & 3 & 2.149 & 0.007 & 0.0058 & 0.0006 & 1.20 & 37.82 \\
\hline & $\mathrm{Fe}-\mathrm{S}$ & 2 & 2.670 & 0.005 & 0.0033 & 0.0004 & & \\
\hline & $\mathrm{Fe}-\mathrm{O}$ & 1 & 1.913 & 0.007 & 0.0013 & 0.0005 & & \\
\hline & $\mathrm{Fe}-\mathrm{Fe}$ & 1 & 4.66 & 0.007 & -0.0094 & 0.0005 & & \\
\hline & $\mathrm{Fe}-\mathrm{O}-\mathrm{Fe}(\mathrm{MS})$ & 2 & 4.741 & 0.007 & -0.0074 & 0.0005 & & \\
\hline & $\mathrm{Fe}-\mathrm{Si}$ & 1 & 2.93 & 0.03 & 0.009 & 0.003 & & \\
\hline & Fe-N-C (MS) & 18 & 3.32 & 0.01 & 0.001 & 0.001 & & \\
\hline \multirow[t]{8}{*}{11} & $\mathrm{Fe}-\mathrm{N}$ & 3 & 2.173 & 0.007 & 0.0055 & 0.0007 & 5.15 & 29.81 \\
\hline & $\mathrm{Fe}-\mathrm{S}$ & 2 & 2.684 & 0.006 & 0.0020 & 0.0004 & & \\
\hline & $\mathrm{Fe}-\mathrm{O}$ & 1 & 1.931 & 0.009 & 0.0029 & 0.0007 & & \\
\hline & $\mathrm{Fe}-\mathrm{Fe}$ & 1 & 4.38 & 0.04 & 0.010 & 0.006 & & \\
\hline & $\mathrm{Fe}-\mathrm{O}-\mathrm{Fe}(\mathrm{MS})$ & 4 & 4.740 & 0.009 & 0.0047 & 0.0005 & & \\
\hline & $\mathrm{Fe}-\mathrm{Si}$ & 1 & 2.91 & 0.02 & 0.001 & 0.001 & & \\
\hline & Fe-N-C (MS) & 18 & 3.37 & 0.01 & 0.002 & 0.002 & & \\
\hline & $\mathrm{Fe}-\mathrm{C}$ & 5 & 4.09 & 0.01 & 0.001 & 0.001 & & \\
\hline
\end{tabular}


Table S3. EXAFS simulations for 3. EXAFS data were fit with EXAFSPAK using paths calculated by FEFF7. Distance and Debye-Waller factors were allowed to float while, coordination numbers were held constant. Goodness of fit is determined by $\mathrm{F}$, defined as $\left[\left(\sum_{i}^{n}\left[k_{i}^{3}\left(E X A F S_{o b s}-\right.\right.\right.\right.$ EXAFS $\left.\left.\left.\left._{\text {(alc }}\right)_{i}\right]\right)^{2} / n\right]^{1 / 2}$.

\begin{tabular}{|c|c|c|c|c|c|c|c|c|}
\hline Fit & Path & $\mathrm{CN}$ & $\mathbf{R}(\AA)$ & \pm & $\sigma^{2}$ & \pm & $\mathrm{E}_{0}(\mathrm{eV})$ & F factor \\
\hline 1 & $\mathrm{Fe}-\mathrm{N}$ & 3 & 2.215 & 0.003 & 0.0050 & 0.0003 & 7.445 & 49.43 \\
\hline 2 & $\mathrm{Fe}-\mathrm{S}$ & 2 & 2.314 & 0.005 & 0.0075 & 0.0003 & $\begin{array}{l}- \\
8.019901\end{array}$ & 49.93 \\
\hline 3 & $\begin{array}{l}\mathrm{Fe}-\mathrm{N} \\
\mathrm{Fe}-\mathrm{S}\end{array}$ & $\begin{array}{l}3 \\
2\end{array}$ & $\begin{array}{l}2.04 \\
2.311\end{array}$ & $\begin{array}{l}0.07 \\
0.006\end{array}$ & $\begin{array}{l}0.09 \\
0.0074\end{array}$ & $\begin{array}{l}0.03 \\
0.0003\end{array}$ & -8.714 & 48.79 \\
\hline 4 & $\begin{array}{l}\mathrm{Fe}-\mathrm{N} \\
\mathrm{Fe}-\mathrm{S} \\
\mathrm{Fe}-\mathrm{N}-\mathrm{C}\end{array}$ & $\begin{array}{l}3 \\
2 \\
24 \\
\end{array}$ & $\begin{array}{l}2.22 \\
2.292 \\
3.598 \\
\end{array}$ & $\begin{array}{l}0.01 \\
0.008 \\
0.007 \\
\end{array}$ & $\begin{array}{l}0.0063 \\
0.012 \\
0.0023 \\
\end{array}$ & $\begin{array}{l}0.0008 \\
0.002 \\
0.0006 \\
\end{array}$ & -1.665 & 42.93 \\
\hline 5 & $\begin{array}{l}\mathrm{Fe}-\mathrm{N} \\
\mathrm{Fe}-\mathrm{S} \\
\mathrm{Fe}-\mathrm{O} \\
\mathrm{Fe}-\mathrm{N}-\mathrm{C}\end{array}$ & $\begin{array}{l}3 \\
2 \\
0.8 \\
24 \\
\end{array}$ & $\begin{array}{l}2.14 \\
2.331 \\
1.681 \\
3.583 \\
\end{array}$ & $\begin{array}{l}0.02 \\
0.004 \\
0.010 \\
0.006 \\
\end{array}$ & $\begin{array}{l}0.028 \\
0.0082 \\
0.001 \\
0.0017 \\
\end{array}$ & $\begin{array}{l}0.004 \\
0.0003 \\
0.002 \\
0.0005 \\
\end{array}$ & -3.6043 & 38.5 \\
\hline 6 & $\begin{array}{l}\mathrm{Fe}-\mathrm{N} \\
\mathrm{Fe}-\mathrm{S} \\
\mathrm{Fe}-\mathrm{O} \\
\mathrm{Fe}-\mathrm{N}-\mathrm{C}\end{array}$ & $\begin{array}{l}3 \\
2 \\
0.8 \\
24 \\
\end{array}$ & $\begin{array}{l}2.211 \\
2.299 \\
1.68 \\
3.607 \\
\end{array}$ & $\begin{array}{l}0.006 \\
0.007 \\
0.01 \\
0.006\end{array}$ & $\begin{array}{l}0.0062 \\
0.015 \\
0.013 \\
0.0024\end{array}$ & $\begin{array}{l}0.0006 \\
0.002 \\
0.002 \\
0.0005 \\
\end{array}$ & 0.177 & 38.81 \\
\hline 7 & $\begin{array}{l}\mathrm{Fe}-\mathrm{N} \\
\mathrm{Fe}-\mathrm{S} \\
\mathrm{Fe}-\mathrm{O} \\
\mathrm{Fe}-\mathrm{N}-\mathrm{C} \\
\mathrm{Fe}-\mathrm{C} \\
\mathrm{Fe}-\mathrm{C}\end{array}$ & $\begin{array}{l}3 \\
2 \\
0.8 \\
24 \\
2 \\
4 \\
\end{array}$ & $\begin{array}{l}2.22 \\
2.326 \\
1.686 \\
3.615 \\
2.96 \\
3.189 \\
\end{array}$ & $\begin{array}{l}0.003 \\
0.007 \\
0.006 \\
0.004 \\
0.01 \\
0.008 \\
\end{array}$ & $\begin{array}{l}0.0054 \\
0.023 \\
0.0112 \\
0.0019 \\
0.008 \\
0.0072 \\
\end{array}$ & $\begin{array}{l}0.0003 \\
0.002 \\
0.001 \\
0.0004 \\
0.001 \\
0.0008 \\
\end{array}$ & 5.315 & 30.94 \\
\hline 8 & $\begin{array}{l}\mathrm{Fe}-\mathrm{N} \\
\mathrm{Fe}-\mathrm{S} \\
\mathrm{Fe}-\mathrm{O} \\
\mathrm{Fe}-\mathrm{N}-\mathrm{C} \\
\mathrm{Fe}-\mathrm{C} \\
\mathrm{Fe}-\mathrm{C}\end{array}$ & $\begin{array}{l}3 \\
2 \\
0.57(7) \\
24 \\
2 \\
4\end{array}$ & $\begin{array}{l}2.220 \\
2.321 \\
1.687 \\
3.613 \\
2.95 \\
3.185\end{array}$ & $\begin{array}{l}0.003 \\
0.007 \\
0.006 \\
0.004 \\
0.01 \\
0.008\end{array}$ & $\begin{array}{l}0.0054 \\
0.022 \\
0.008 \\
0.0019 \\
0.007 \\
0.0076\end{array}$ & $\begin{array}{l}0.0003 \\
0.002 \\
0.001 \\
0.0004 \\
0.001 \\
0.0009\end{array}$ & 4.79 & 30.25 \\
\hline
\end{tabular}


Table S4. EXAFS simulations for 4. EXAFS data were fit with EXAFSPAK using paths calculated by FEFF7. Distance and Debye-Waller factors were allowed to float while, coordination numbers were held constant. Goodness of fit is determined by $\mathrm{F}$, defined as $\left[\left(\sum_{i}^{n}\left[k_{i}^{3}\left(E X A F S_{o b s}-\right.\right.\right.\right.$ $\left.\left.\left.\left.\operatorname{EXAFS}_{\text {calc }}\right)_{i}\right]\right)^{2} / n\right]^{1 / 2}$.

\begin{tabular}{lllllllll} 
Fit & Path & $\mathbf{C N}$ & $\mathbf{R}(\mathbf{\AA})$ & $\mathbf{\pm}$ & $\boldsymbol{\sigma}^{\mathbf{2}}$ & $\mathbf{\pm}$ & $\mathbf{E}_{\mathbf{0}}(\mathbf{e V})$ & $\mathbf{F}$ factor \\
\hline \hline 1 & $\mathrm{Fe}-\mathrm{N}$ & 3 & 2.287 & 0.003 & 0.0014 & 0.0002 & 1.562 & 44.65 \\
\hline 2 & $\mathrm{Fe}-\mathrm{S}$ & 2 & 2.380 & 0.005 & 0.0040 & 0.0002 & -14.412 & 43.79 \\
\hline 3 & $\mathrm{Fe}-\mathrm{S}$ & 2 & 2.379 & 0.015 & 0.00626 & 0.0022 & -6.282 & 41.63 \\
& $\mathrm{Fe}-\mathrm{N}$ & 3 & 2.306 & 0.021 & 0.00429 & 0.0025 & & \\
\hline 4 & $\mathrm{Fe}-\mathrm{S}$ & 2 & 2.388 & 0.008 & 0.0084 & 0.0017 & -6.622 & 35.55 \\
& $\mathrm{Fe}-\mathrm{N}$ & 3 & 2.275 & 0.008 & 0.0046 & 0.0014 & & \\
\hline 5 & $\mathrm{Fe}-\mathrm{OH}$ & 1 & 1.911 & 0.008 & 0.0070 & 0.0011 & & 28.75 \\
& $\mathrm{Fe}-\mathrm{S}$ & 2 & 2.391 & 0.005 & 0.0060 & 0.0011 & -9.750 & \\
& $\mathrm{Fe}-\mathrm{N}$ & 3 & 2.246 & 0.018 & 0.0100 & 0.0042 & & \\
& $\mathrm{Fe}-\mathrm{OH}$ & 1 & 1.907 & 0.012 & 0.0056 & 0.0010 & & \\
& $\mathrm{Fe}-\mathrm{N}-\mathrm{C}$ & 24 & 3.293 & 0.011 & 0.0029 & 0.0006 & &
\end{tabular}



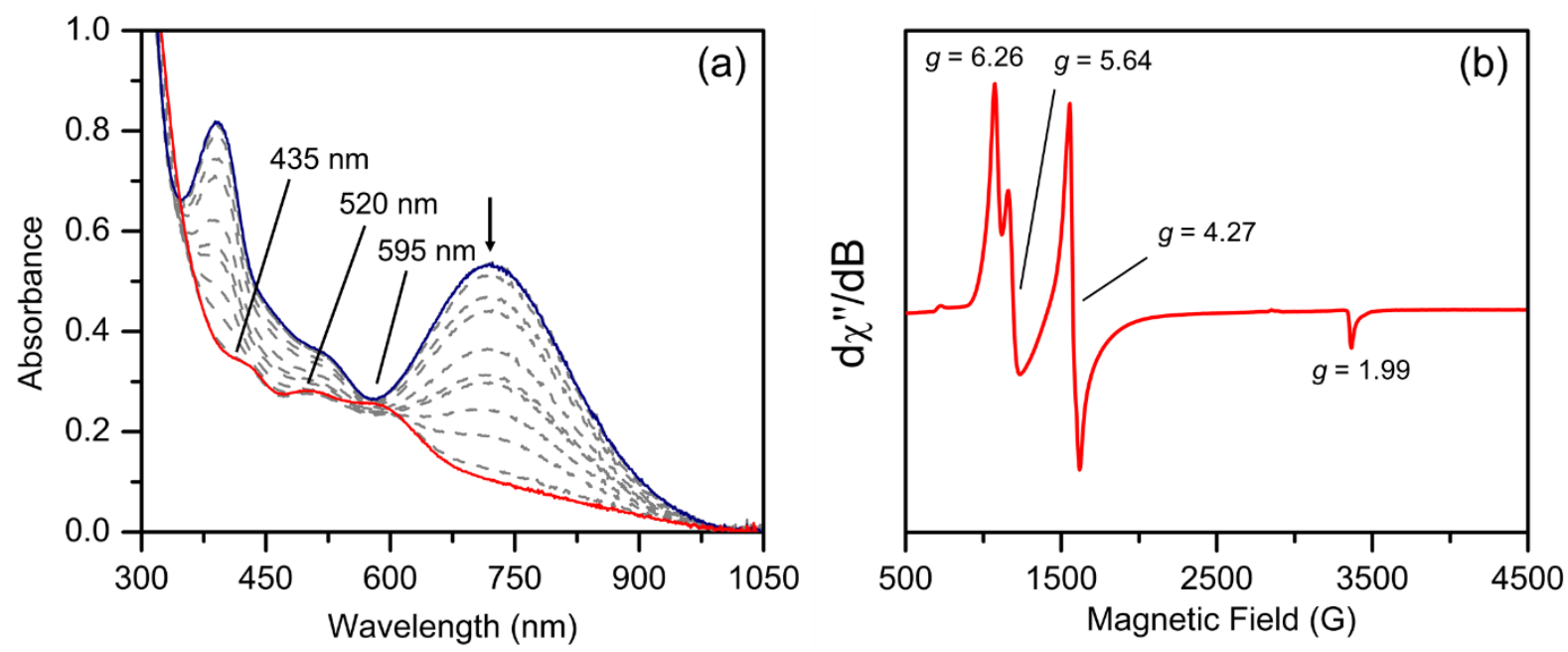

Figure S14. (a) UV-vis spectra of the reaction of 2 with 2 equiv of [LutH]BF $4(100 \mu \mathrm{L}, 9.1 \mathrm{mM}$ in 6:1 2-MeTHF/MeOH) in 2-MeTHF over $50 \mathrm{~min}$. Blue line represents 2, red line represents final reaction mixture, and grey dashed lines represent scans prior to full decay of 2. (b) X-band EPR spectrum of the reaction of 2 with 2 equiv of [LutH]BF $4(50 \mu \mathrm{L}, 50 \mathrm{mM}$ in 1:1 2-MeTHF/MeOH) in 2-MeTHF. Conditions: microwave freq $=9.4106 \mathrm{GHz}$; microwave power $=2.0 \mathrm{~mW}$; modulation amp. $=10 \mathrm{G}$; receiver gain $=5 \times 10^{3}$. 


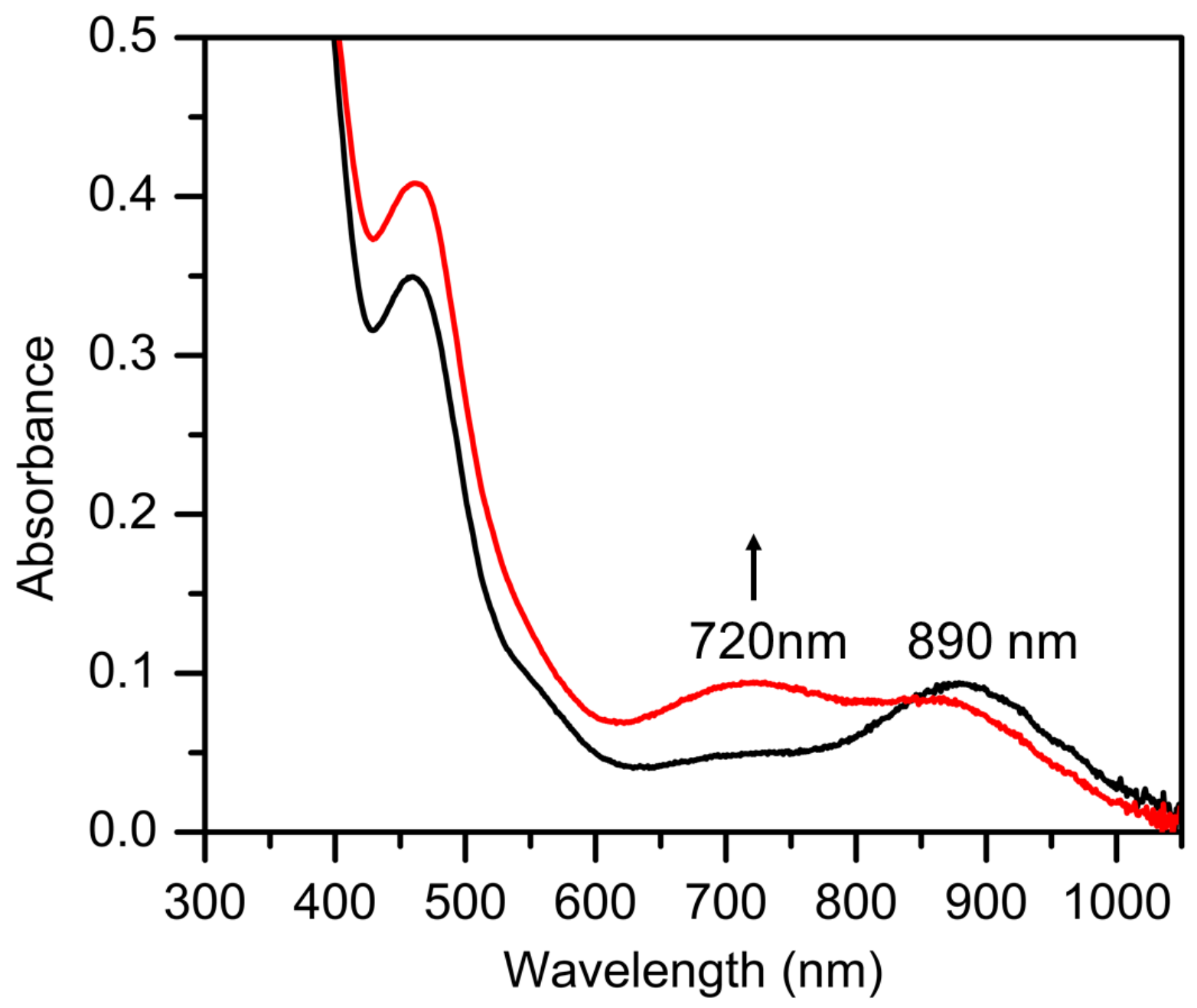

Figure S15. UV-vis spectra showing decay of $\mathbf{3}$ (black line) in the presence of UV light in 2MeTHF at $-135^{\circ} \mathrm{C}$. Red line represents spectrum after 40 min of illumination with UV light. 


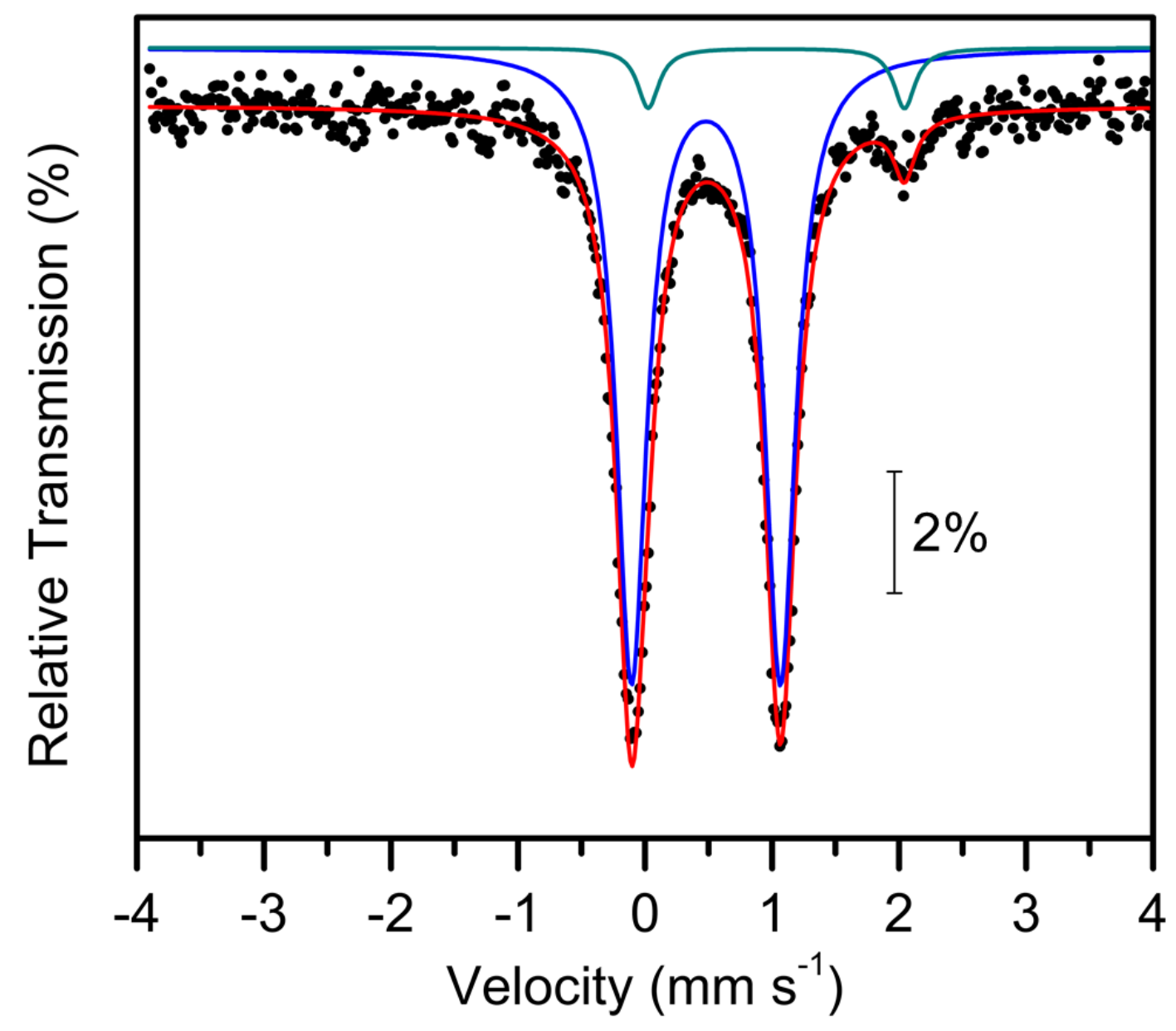

Figure S16. Zero-field ${ }^{57} \mathrm{Fe}$ Mössbauer spectrum of UV photodecay product of $\mathbf{3}\left({ }^{57} \mathbf{F e}\right)$ as a frozen matrix collected at $80 \mathrm{~K}$ in 2-MeTHF. Overall fit shown as a red line. Fits for sub-spectra shown as blue and green lines. The fit for the major quadrupole doublet (blue line) gives parameters $\delta=$ $0.48 \mathrm{~mm} \mathrm{~s}^{-1},\left|\Delta \mathrm{E}_{\mathrm{Q}}\right|=1.17 \mathrm{~mm} \mathrm{~s}^{-1}$, and $\Gamma_{\mathrm{L}, \mathrm{R}}=0.29 \mathrm{~mm} \mathrm{~s}^{-1}$ and makes up $94 \%$ of the total fit. A minor quadrupole doublet (green line) corresponding to $6 \%$ of the fit gives parameters $\delta=1.03$ $\mathrm{mm} \mathrm{s}^{-1},\left|\Delta \mathrm{E}_{\mathrm{Q}}\right|=2.02 \mathrm{~mm} \mathrm{~s}^{-1}$, and $\Gamma_{\mathrm{L}, \mathrm{R}}=0.20 \mathrm{~mm} \mathrm{~s}^{-1}$. 


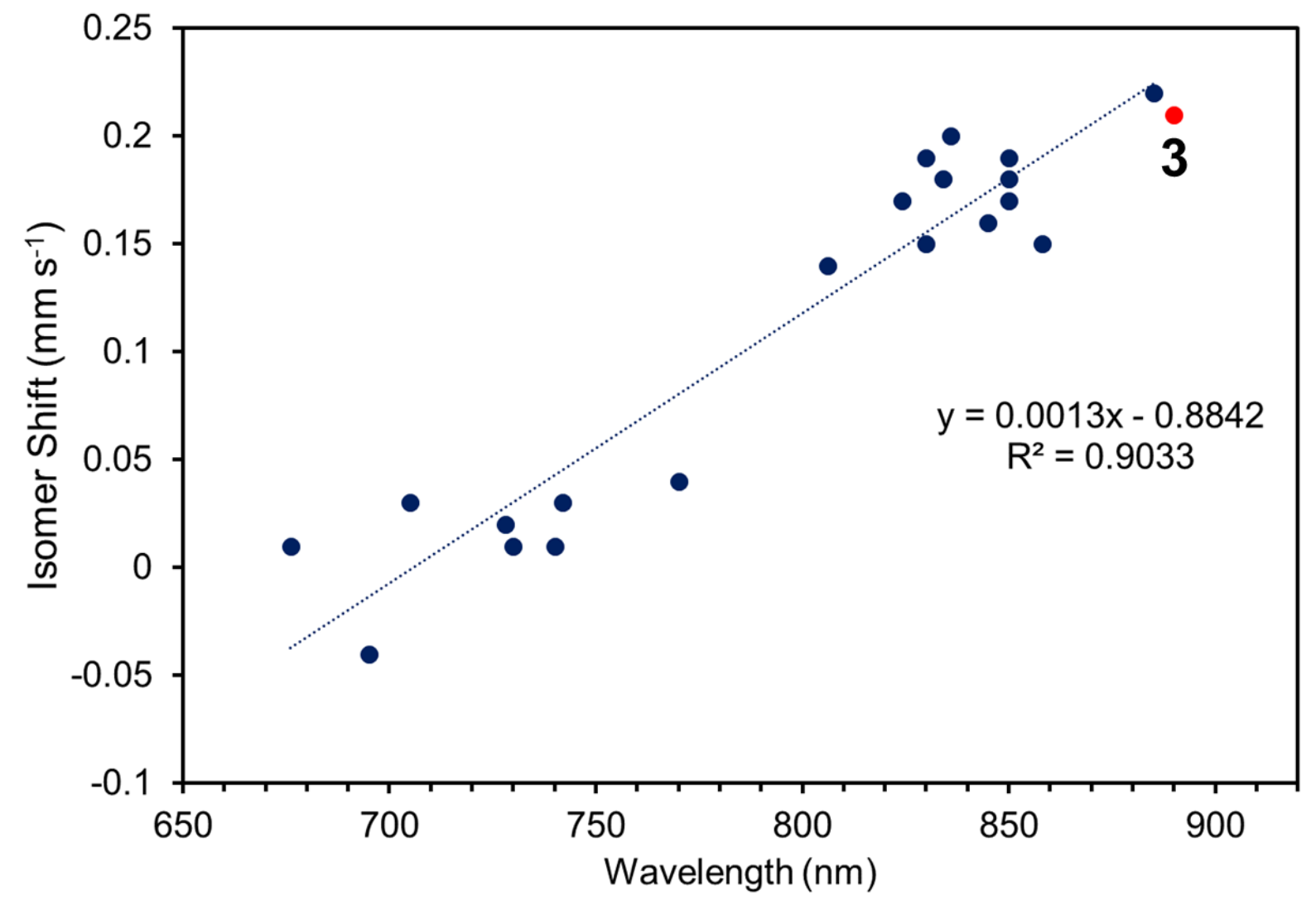

Figure S17. Plot of isomer shift versus wavelength of UV-vis low energy peak for a range of $\mathrm{Fe}^{\mathrm{IV}}(\mathrm{O})(S=1)$ complexes. Plot derived from data in reference 2. 


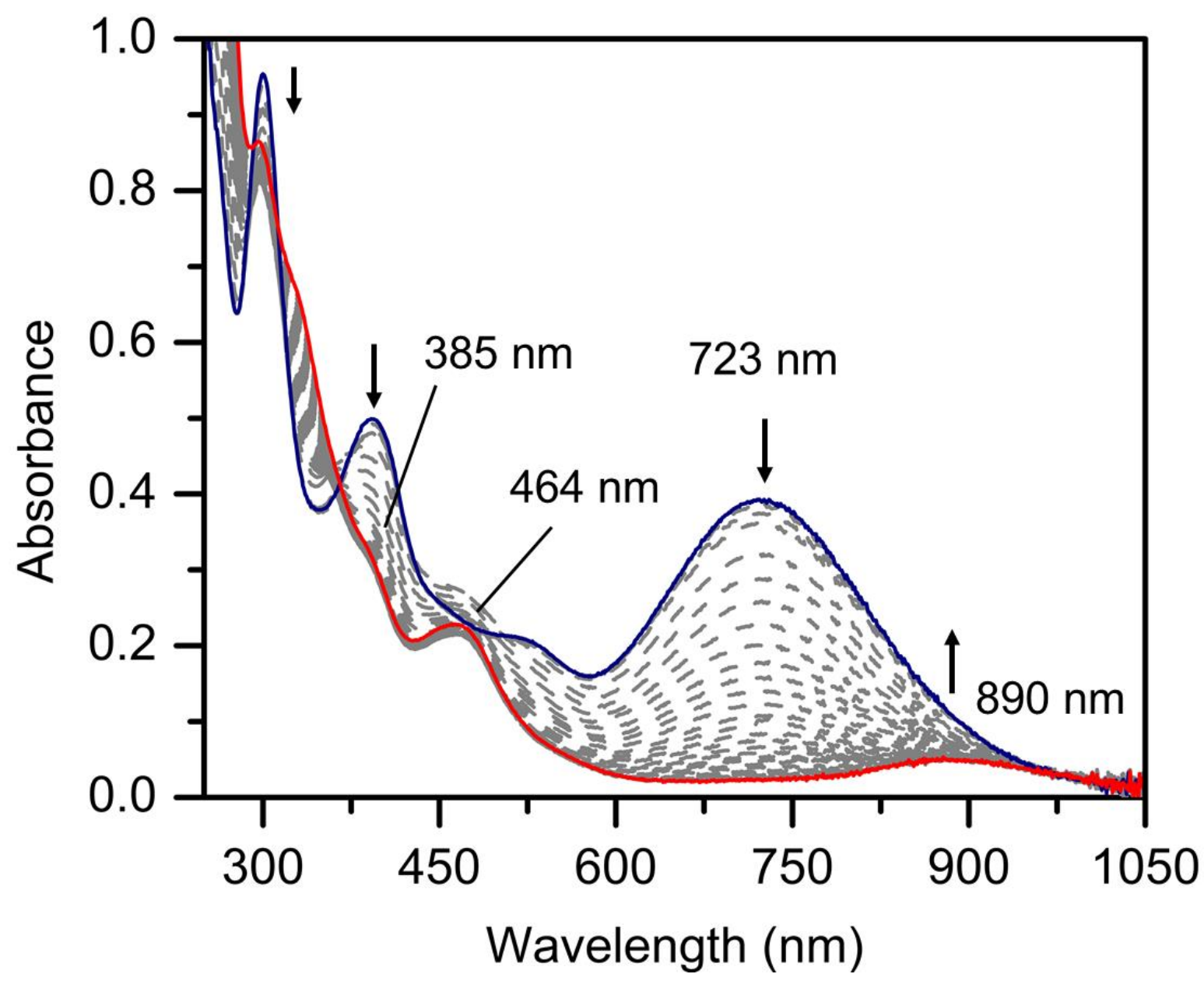

Figure S18. UV-vis spectra showing thermal decay of 2 to 3 from $-135^{\circ} \mathrm{C}$ to $-105^{\circ} \mathrm{C}$ in 2-MeTHF. 


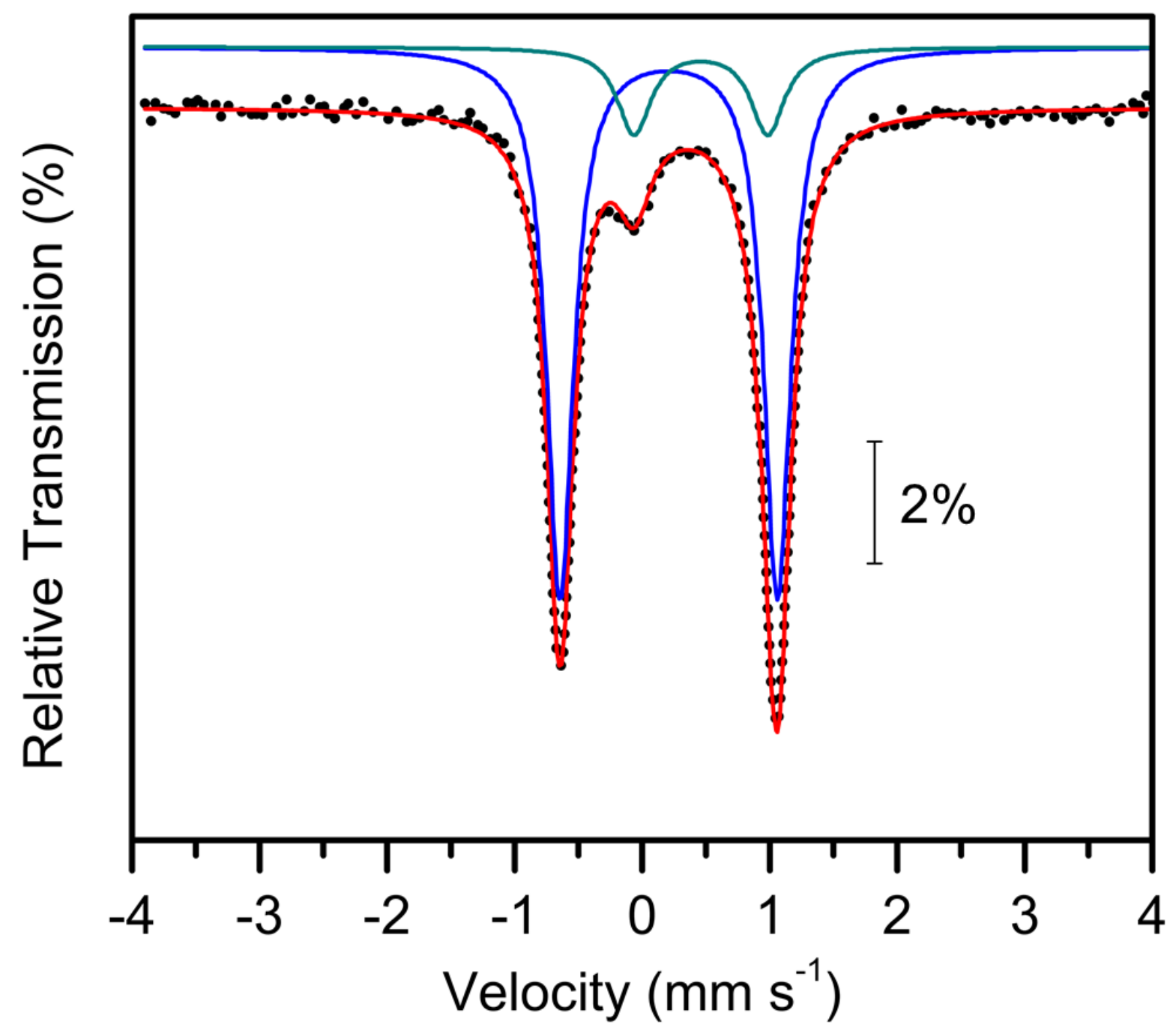

Figure S19. Zero-field ${ }^{57} \mathrm{Fe}$ Mössbauer spectrum of $\mathbf{3}\left({ }^{57} \mathbf{F e}\right)$ at $80 \mathrm{~K}$ in 2-MeTHF generated from thermolysis of $2\left({ }^{57} \mathbf{F e}\right)$ at $-105{ }^{\circ} \mathrm{C}$. Overall fit shown as a red line. Fits for sub-spectra shown as blue and green lines. The major quadrupole doublet (blue line), corresponding to $3{ }^{57} \mathbf{F e}$ ) exhibits parameters with $\delta=0.21 \mathrm{~mm} \mathrm{~s}^{-1},\left|\Delta \mathrm{E}_{\mathrm{Q}}\right|=1.70 \mathrm{~mm} \mathrm{~s}^{-1}$, and $\Gamma_{\mathrm{L}, \mathrm{R}}=0.26 \mathrm{~mm} \mathrm{~s}^{-1}$ that makes up $84 \%$ of the total fit. A minor quadrupole doublet (green line) with parameters $\delta=0.46 \mathrm{~mm} \mathrm{~s}^{-1},\left|\Delta \mathrm{E}_{\mathrm{Q}}\right|$ $=1.05 \mathrm{~mm} \mathrm{~s}^{-1}$, and $\Gamma_{\mathrm{L}, \mathrm{R}}=0.32 \mathrm{~mm} \mathrm{~s}^{-1}$ makes up $16 \%$ of the total fit. Slight differences in the quadrupole splitting for $3\left({ }^{57} \mathbf{F e}\right)$ generated via photolysis and thermolysis are noted and could be attributed to slight differences in the local environment for each method of generating $3\left({ }^{57} \mathbf{F e}\right)$. 


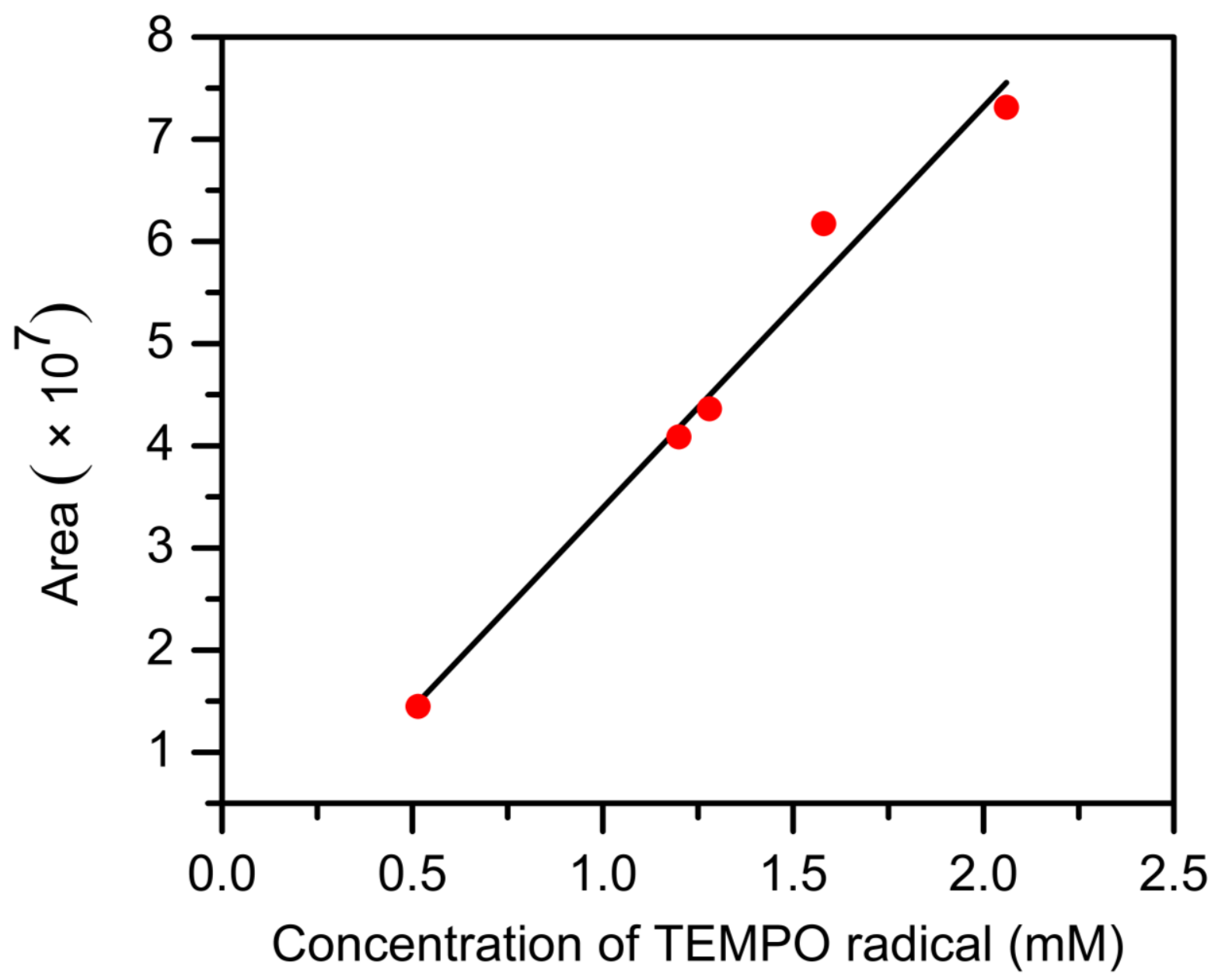

Figure S21. X-band EPR spectroscopy calibration curve for TEMPO radical. The calibration curve was generated from EPR spectra collected in 2-MeTHF at $40 \mathrm{~K}$. The area for each data point was obtained from double integration of the EPR spectrum. 


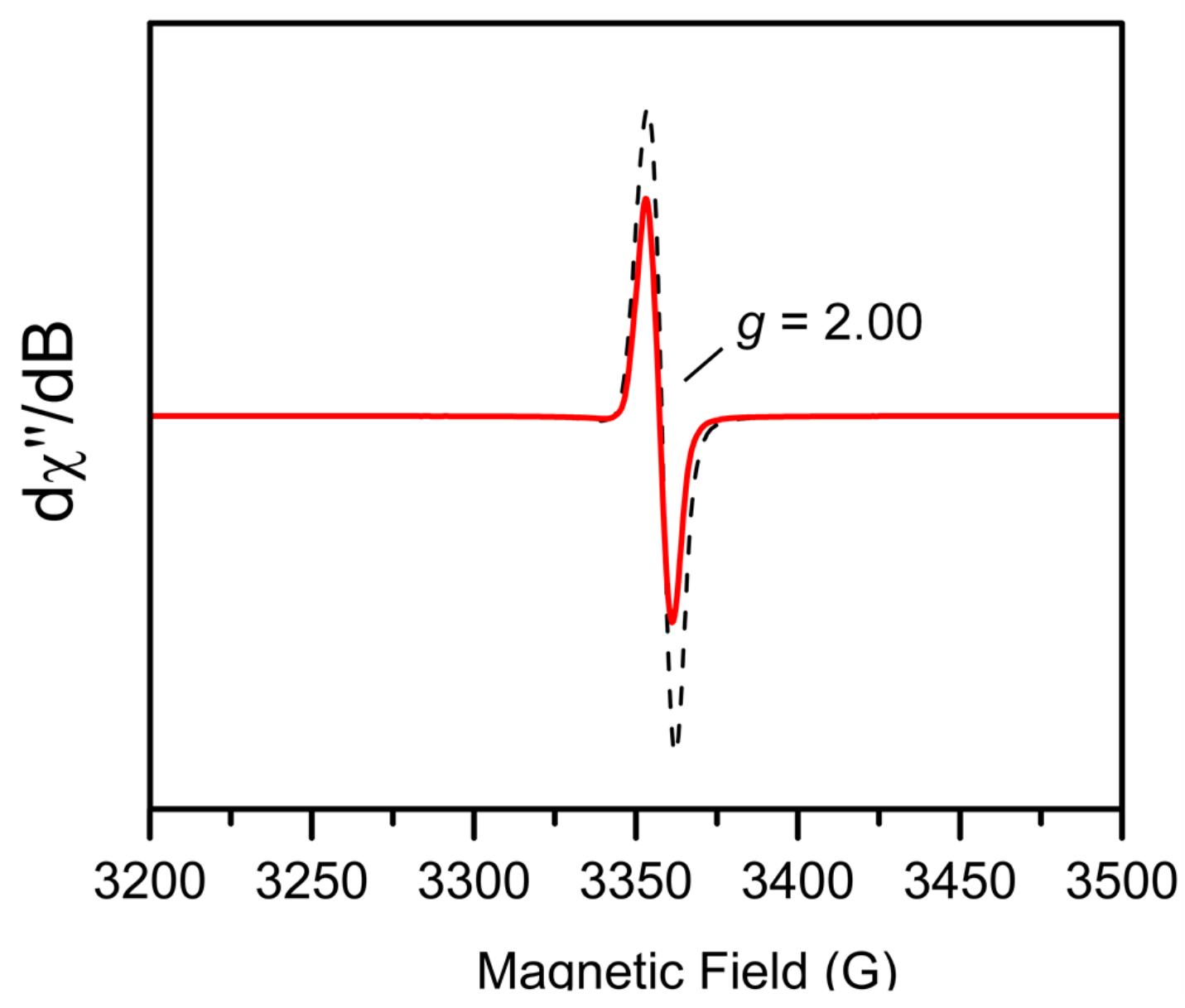

Figure S22. Representative X-band EPR spectrum of reaction of 3 with 4-OMe-dtbp (7 equiv) $(0.99 \mathrm{mM})$ (red line) and comparison with the spectrum for 2,4,6-tri-tert-butylphenoxyl radical $\left(t^{\bullet}{ }^{\bullet}\right)(1.3 \mathrm{mM})$ as a standard (black dashed line). Spectra were collected in 2-MeTHF at $40 \mathrm{~K}$. Double integration of the phenoxyl radical signal from reactions of 3 with 4-OMe-dtbp and comparison with the calibration curve in Figure S21 reveals that 2,6-di-tert-butyl-4methoxyphenoxyl radical is formed with an average yield of $75 \%$. Data listed in Table S6. Conditions: Microwave freq. $=9.416 \mathrm{GHz}$; microwave power $=2 \times 10^{3} \mathrm{~mW}$; mod. amp. $=2.5 \mathrm{G}$; rec. gain $=5 \times 10^{3}$. 


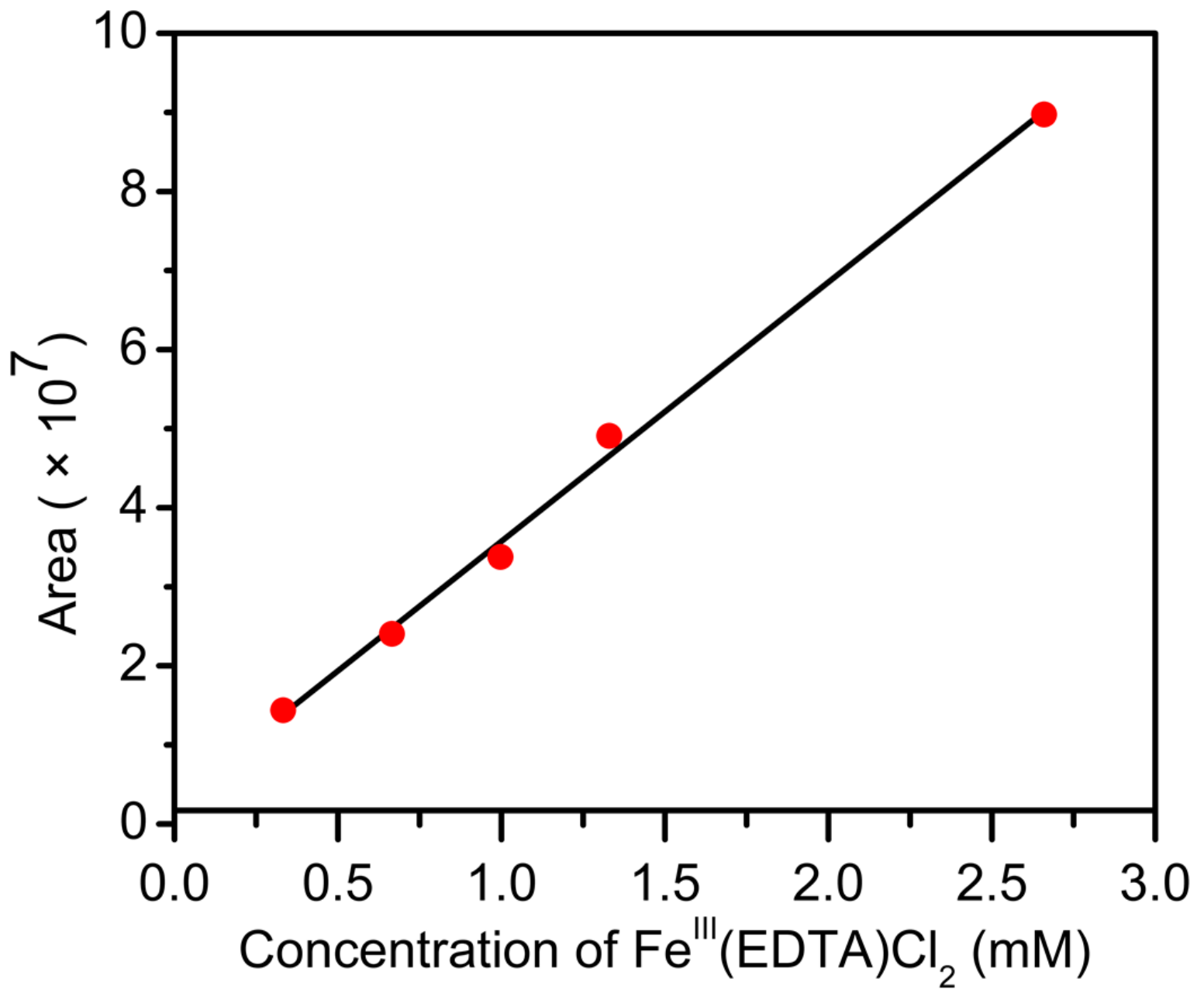

Figure S23. X-band EPR spectroscopy calibration curve for $\mathrm{Fe}^{\mathrm{III}}(\mathrm{EDTA}) \mathrm{Cl}_{2}$. The calibration curve was generated from EPR spectra collected in 1:1 glycerol/water at $20 \mathrm{~K}$. The area for each data point was obtained from double integration of the EPR spectrum. Data listed in Table S5. 


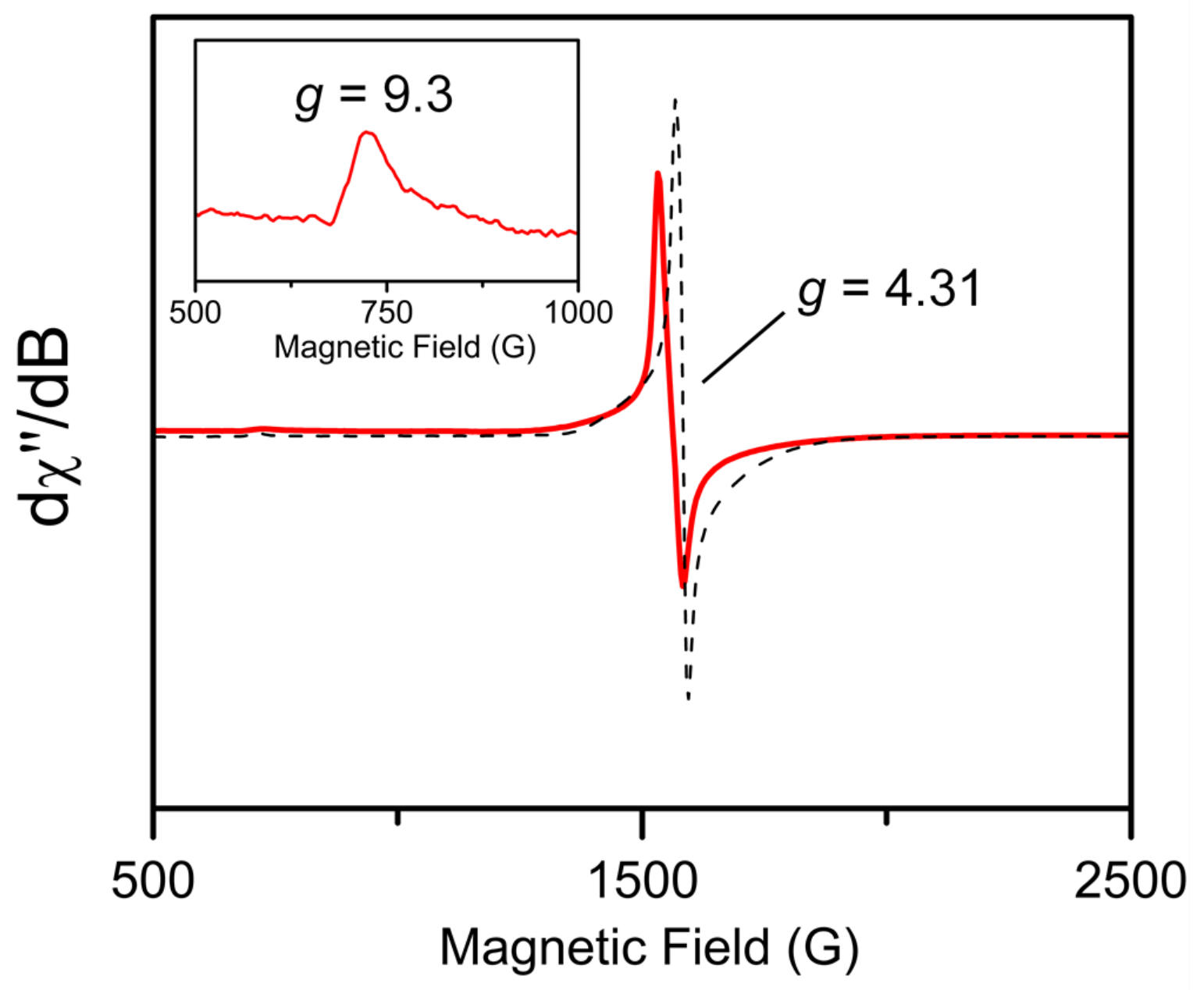

Figure S24. Representative X-band EPR spectrum of reaction of 3 with 4-OMe-dtbp (0.99 mM) (7 equiv) in 2-MeTHF (red line) and comparison with $\mathrm{Fe}^{\mathrm{III}}(\mathrm{EDTA}) \mathrm{Cl}_{2}(1 \mathrm{mM})$ standard in 1:1 glycerol/ $\mathrm{H}_{2} \mathrm{O}$ (black dashed line). Inset: Spectrum from $500-1000 \mathrm{G}$ showing $g=9.3$ signal. Spectra were collected in 2-MeTHF at $20 \mathrm{~K}$. Double integration of the $\mathrm{Fe}^{\mathrm{III}}$ signal from reactions of 3 with 4-OMe-dtbp and comparison with the calibration curve in Figure S23 reveals that an average of 1.04 equiv of Fe ${ }^{\mathrm{III}}$ product is generated. Data listed in Table S7. Conditions: Microwave freq. $=9.4139 \mathrm{GHz}$; microwave power $=0.20 \mathrm{~mW}$; mod. amp. $=10 \mathrm{G}$; rec. gain $=5 \times 10^{3}$. 
Table S5. EPR data for the calibration curves in Figure S21 and S23

\begin{tabular}{|c|c|}
\hline Concentration (mM) & Double Integration $\left(\times 10^{-7}\right)$ \\
\hline \multicolumn{2}{|c|}{ TEMPO Radical Calibration Curve } \\
\hline 0.515 & 1.45 \\
\hline 1.2 & 4.09 \\
\hline 1.28 & 4.36 \\
\hline 1.58 & 6.18 \\
\hline 2.06 & 7.31 \\
\hline \multicolumn{2}{|c|}{$\mathrm{Fe}^{I I I}(\mathrm{EDTA}) \mathrm{Cl}_{2}$ Calibration Curve } \\
\hline 0.33 & 0.58 \\
\hline 0.67 & 1.02 \\
\hline 1.00 & 1.47 \\
\hline 1.33 & 2.17 \\
\hline 2.00 & 2.34 \\
\hline 2.66 & 4.03 \\
\hline
\end{tabular}


Table S6. Integrated values for $g=2$ signal from EPR spectra of three independent runs of the reaction of $\mathbf{3}$ with $4-\mathrm{OMe}-\mathrm{dtbp}$ in $2-\mathrm{MeTHF}$ and ttbp ${ }^{\bullet}$ standard.

\begin{tabular}{|c|c|c|}
\hline Sample & Double Integration & Equiv phenoxyl radical \\
\hline Run 1 & 24950000 & 0.74 \\
\hline Run 2 & 22630000 & 0.67 \\
\hline \multirow[t]{3}{*}{ Run 3} & 26440000 & 0.79 \\
\hline & Ave & 0.74 \\
\hline & Std Dev & 0.06 \\
\hline Authentic & & \\
\hline $\begin{array}{l}\text { Phenoxyl } \\
(1.3 \mathrm{mM})\end{array}$ & 47230000 & 1.01 \\
\hline
\end{tabular}

Table S7. Integrated values for $g=4.3$ signal from EPR spectra of three independent runs of the reaction of 3 with $4-\mathrm{OMe}-\mathrm{dtbp}$ in 2-MeTHF.

\begin{tabular}{ccc}
\hline Sample & Double Integration & Equiv Fe $^{\text {III }}$ \\
\hline Run 1 & 16110000 & 1.10 \\
Run 2 & 14750000 & 1.00 \\
Run 3 & 15330000 & 1.04 \\
\hline & Ave & $\mathbf{1 . 0 5}$ \\
& Std Dev & 0.05 \\
\hline
\end{tabular}




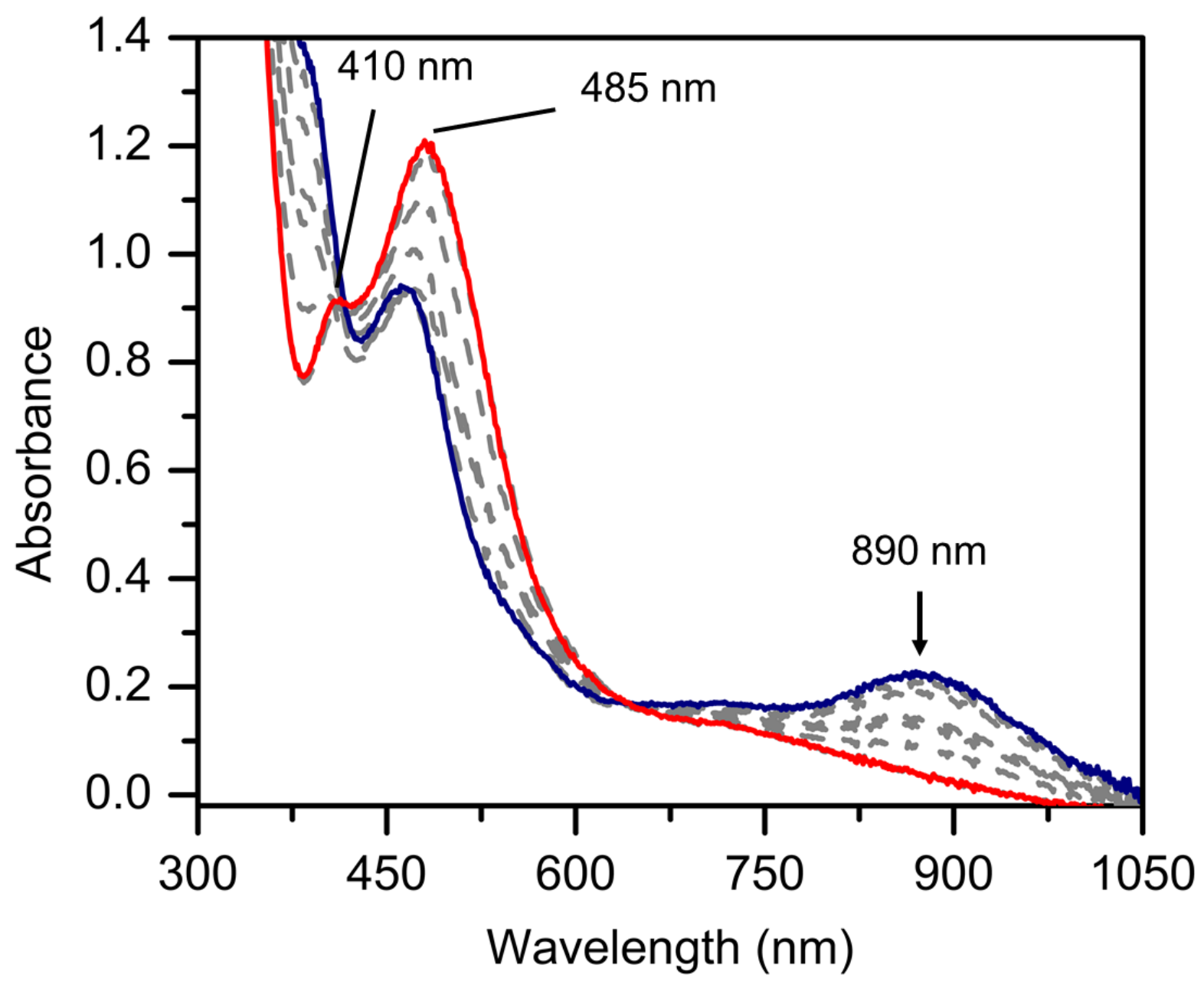

Figure S25. UV-vis spectra of reaction of $3(0.5 \mathrm{mM})$ with 4-OMe-TEMPOH (37 equiv) in 2MeTHF at $-135{ }^{\circ} \mathrm{C}$ over $8 \mathrm{~min}$. 

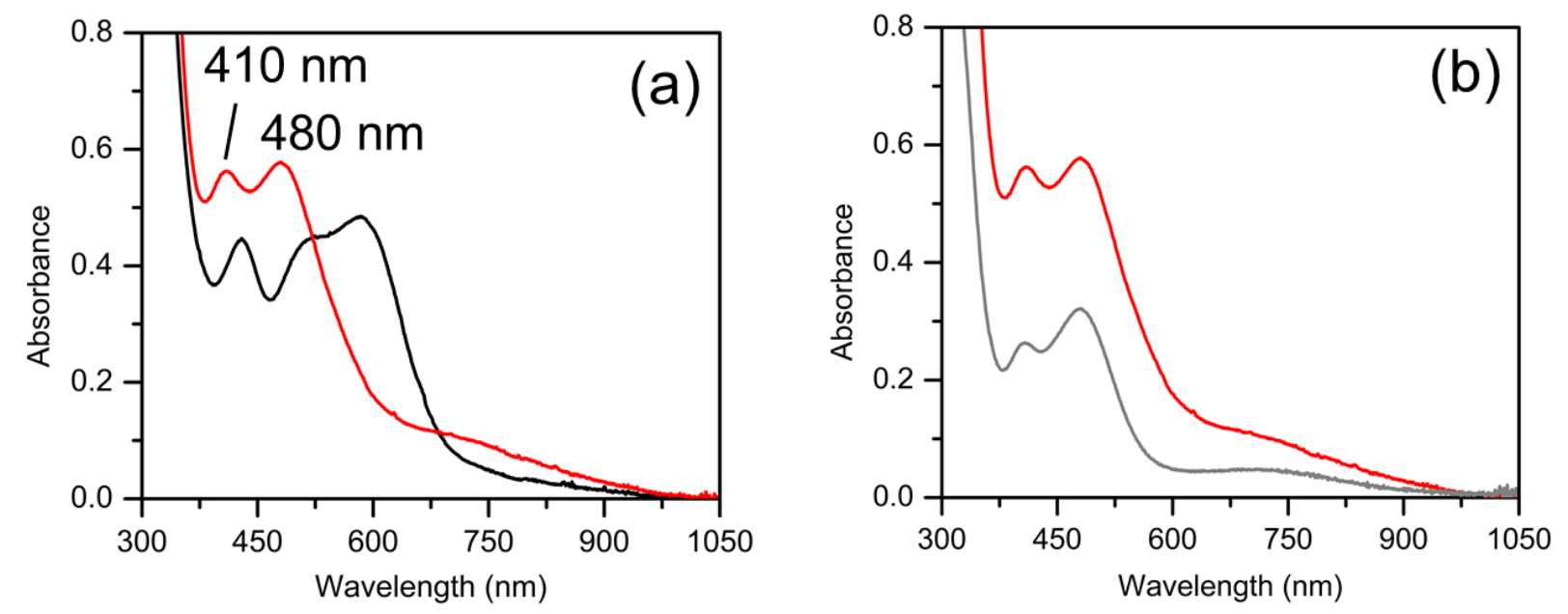

Figure S26. UV-vis spectra of (a) reaction of $\mathbf{1}^{\mathbf{0 x}}$ (black line) with 1 equiv of $n \mathrm{Bu}_{4} \mathrm{NOH} \cdot 30 \mathrm{H}_{2} \mathrm{O}$ in THF to produce $\mathbf{4}$ (red line) and (b) comparison of the reaction product of $\mathbf{1}^{\mathbf{0 x}}$ with 1 equiv of $n \mathrm{Bu} 4 \mathrm{NOH} \bullet 30 \mathrm{H}_{2} \mathrm{O}$ at $-80{ }^{\circ} \mathrm{C}$ (red line) with reaction product of $\mathbf{3}$ with excess TEMPOH in THF at $-105{ }^{\circ} \mathrm{C}$ (grey line). 


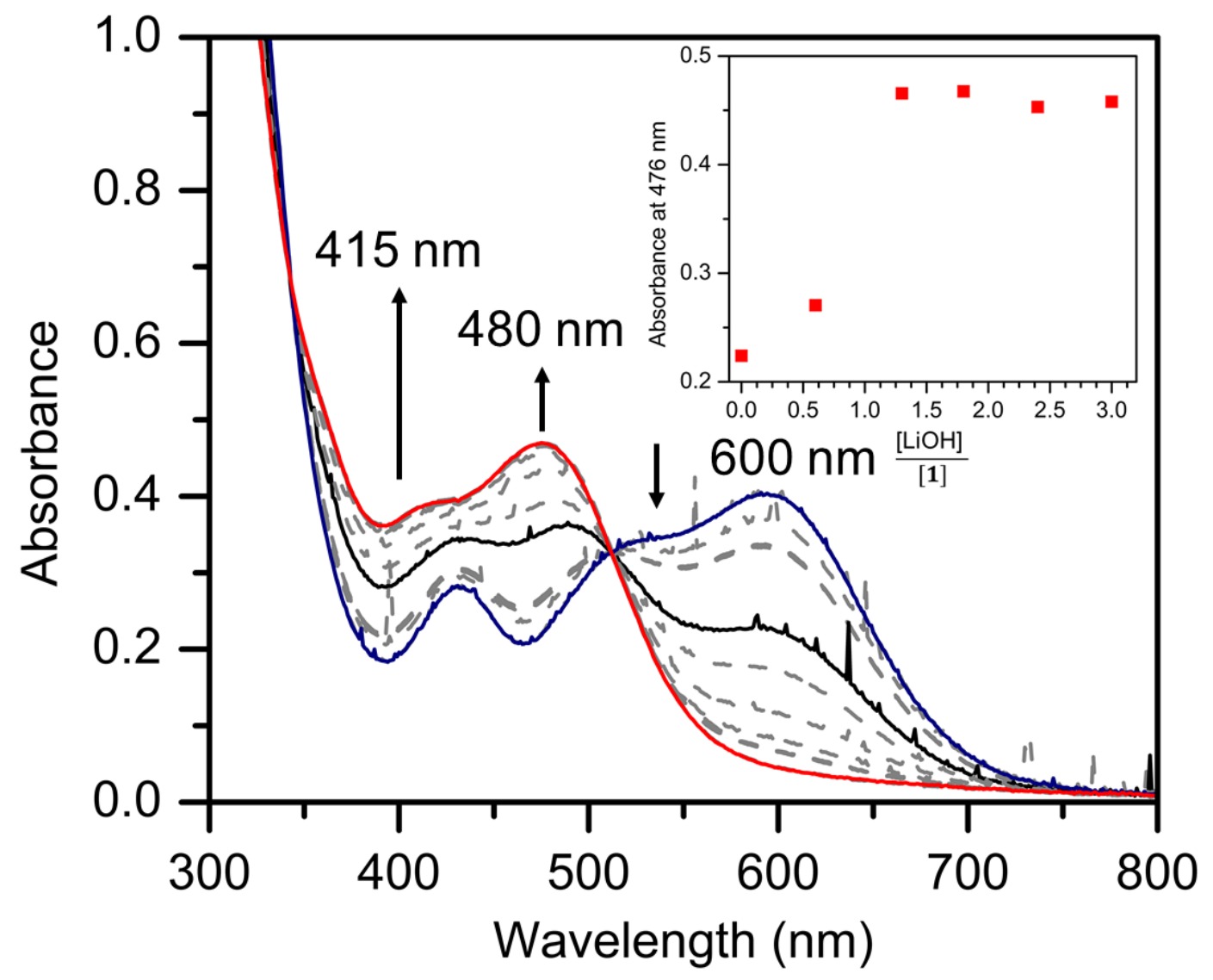

Figure S27. UV-vis spectra showing titration of $\mathbf{1}^{\mathbf{0 x}}$ (blue line) with 1 equiv of $\mathrm{LiOH}(9.2 \mathrm{mM}$ in $\mathrm{MeOH}$ ) in 2-MeTHF to produce 4 (red line) at $-80{ }^{\circ} \mathrm{C}$. Black line represents reaction mixture after addition of 0.5 equiv $\mathrm{LiOH}$. Grey dashed lines represent scans between each addition of $\mathrm{LiOH}$. Minor differences between this reaction and the reaction of $\mathbf{3}$ with $\mathrm{H}$-atom donors are noted and are attributed to the presence of $\mathrm{Li}^{+}$and/or $\mathrm{MeOH}$ in the reaction mixture. Inset: Plot of equiv of $\mathrm{LiOH}$ added versus absorbance at $476 \mathrm{~nm}$ indicating the 1:1 stoichiometry and lack of further reactivity with addition of excess $\mathrm{OH}^{-}$. 


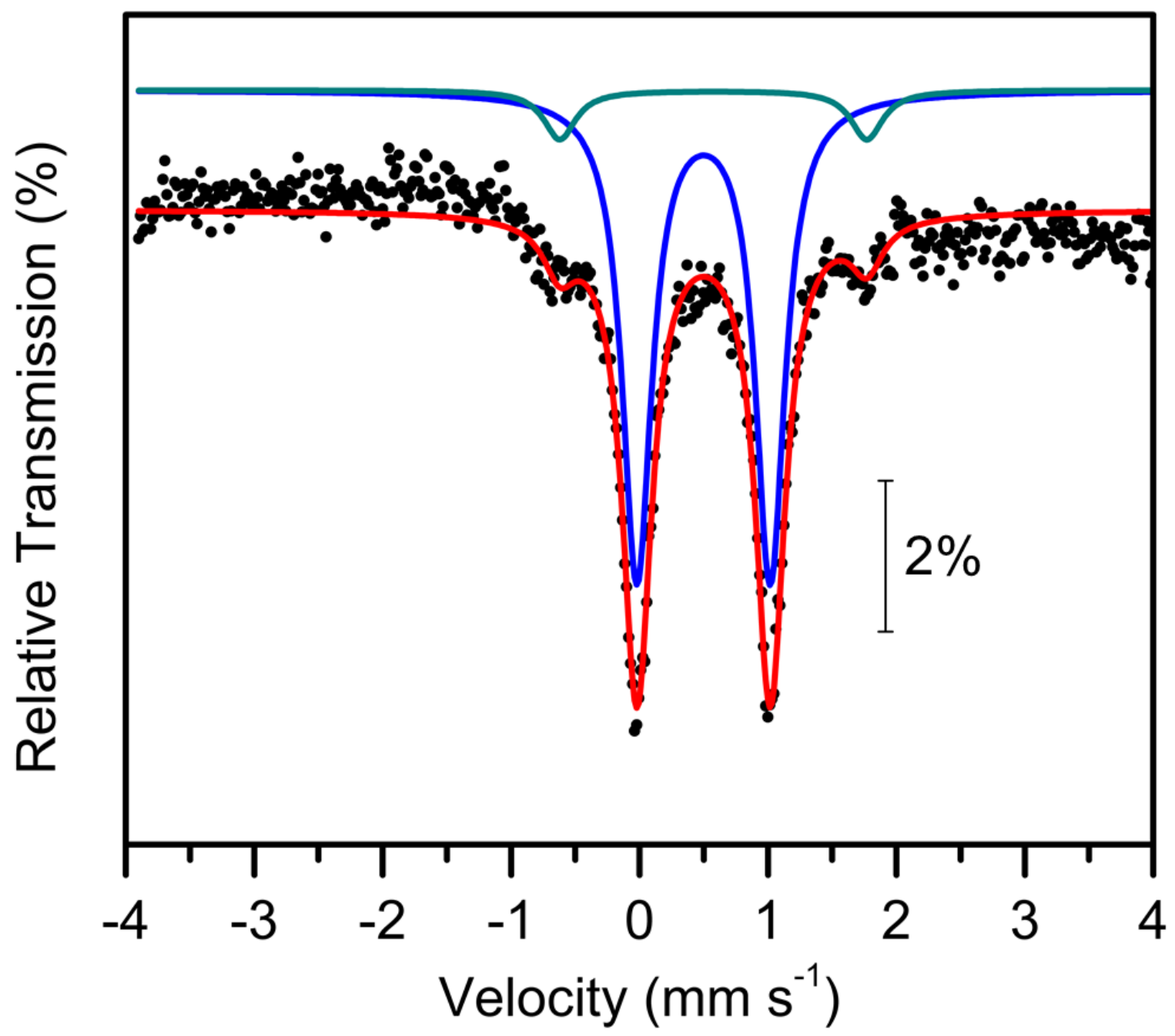

Figure S28. Zero-field ${ }^{57} \mathrm{Fe}$ Mössbauer spectrum at $80 \mathrm{~K}$ of reaction of $\mathbf{1}^{\mathbf{0 x}}\left({ }^{57} \mathbf{F e}\right)+1$ equiv of $\mathrm{LiOH}(0.2 \mathrm{mM}$ in $\mathrm{MeOH})$ at $-80^{\circ} \mathrm{C}$ in 2-MeTHF Overall fit shown as a red line. Fits for subspectra shown as blue and green lines. The major quadrupole doublet (blue line), corresponding to 4, exhibits parameters with $\delta=0.50 \mathrm{~mm} \mathrm{~s}^{-1},\left|\Delta \mathrm{E}_{\mathrm{Q}}\right|=1.04 \mathrm{~mm} \mathrm{~s}^{-1}$, and $\Gamma_{\mathrm{L}, \mathrm{R}}=0.28 \mathrm{~mm} \mathrm{~s}^{-1}$ that makes up $90 \%$ of the total fit. A minor unknown quadrupole doublet (green line) with parameters $\delta=0.57 \mathrm{~mm} \mathrm{~s}^{-1},\left|\Delta \mathrm{E}_{\mathrm{Q}}\right|=2.39 \mathrm{~mm} \mathrm{~s}^{-1}$, and $\Gamma_{\mathrm{L}, \mathrm{R}}=0.30 \mathrm{~mm} \mathrm{~s}^{-1}$ makes up $10 \%$ of the total fit. Slight differences in the parameters for this reaction and of $4\left({ }^{57} \mathbf{F e}\right)$ from reaction of $3\left({ }^{57} \mathbf{F e}\right)$ with $\mathrm{H}$-atom donors are noted and are attributed to the presence of $\mathrm{Li}^{+}$and/or $\mathrm{MeOH}$ in the reaction mixture as seen with the UV-vis spectrum. 
Table S8. Summary of all Mössbauer data reported ${ }^{a, b}$

\begin{tabular}{|c|c|c|c|c|c|c|}
\hline Complex & Subsite & $\delta,\left|\Delta \mathbf{E}_{\mathbf{Q}}\right|$ & $\%$ of fit & $\Gamma_{\mathrm{L}}, \Gamma_{\mathrm{R}}$ & Temperature & Figure \# \\
\hline \multirow{2}{*}{$1\left({ }^{57} \mathrm{Fe}\right)^{c}$} & Subsite 1 & $0.92,2.27$ & $85 \%$ & $0.24,0.24$ & \multirow{2}{*}{$5 \mathrm{~K}$} & \multirow{2}{*}{ S2 } \\
\hline & Subsite 2 & $1.11,2.52$ & $15 \%$ & $0.35,0.35$ & & \\
\hline $1^{0 x}\left({ }^{57} \mathrm{Fe}\right)$ & - & $0.45,3.6$ & $100 \%$ & $0.74,0.43$ & $80 \mathrm{~K}$ & S8 \\
\hline $2\left({ }^{57} \mathrm{Fe}\right)$ & - & $0.53,0.76$ & $100 \%$ & $0.27,0.27$ & $80 \mathrm{~K}$ & 5 \\
\hline \multirow{3}{*}{$2\left({ }^{57} \mathrm{Fe}\right)$} & Subsite 1 & $0.54,0.79$ & $81 \%$ & $0.26,0.26$ & \multirow{3}{*}{$5 \mathrm{~K}$} & \multirow{3}{*}{ S10 } \\
\hline & Subsite 2 & $0.41,2.09$ & $8 \%$ & $0.23,0.23$ & & \\
\hline & Subsite 3 & $1.11,2.44$ & $11 \%$ & $0.33,0.33$ & & \\
\hline $2\left({ }^{57} \mathrm{Fe}\right)^{d}$ & - & $0.54,0.78$ & $100 \%$ & $0.26,0.26$ & $5 \mathrm{~K}$ & S11 \\
\hline \multirow{2}{*}{$3\left({ }^{57} \mathrm{Fe}\right)^{e}$} & Subsite 1 & $0.21,1.57$ & $80 \%$ & $0.27,0.27$ & \multirow{2}{*}{$80 \mathrm{~K}$} & \multirow{2}{*}{10} \\
\hline & Subsite 2 & $0.50,1.16$ & $20 \%$ & $0.27,0.27$ & & \\
\hline \multirow{2}{*}{$3\left({ }^{57} \mathbf{F e}\right)^{f}$} & Subsite 1 & $0.21,1.70$ & $84 \%$ & 0.260 .26 & \multirow{2}{*}{$80 \mathrm{~K}$} & \multirow{2}{*}{ S19 } \\
\hline & Subsite 2 & $0.46,1.05$ & $16 \%$ & $0.32,0.32$ & & \\
\hline \multirow{2}{*}{ Photodecay of $3\left({ }^{57} \mathrm{Fe}\right)$} & Subsite 1 & $0.48,1.17$ & $94 \%$ & $0.29,0.29$ & \multirow{2}{*}{$80 \mathrm{~K}$} & \multirow{2}{*}{ S16 } \\
\hline & Subsite 2 & $1.03,2.02$ & $6 \%$ & $0.20,0.20$ & & \\
\hline $4\left({ }^{57} \mathrm{Fe}\right)^{g}$ & - & $0.49,1.08$ & $100 \%$ & $0.32,0.32$ & $80 \mathrm{~K}$ & 15 \\
\hline \multirow{2}{*}{$4\left({ }^{57} \mathrm{Fe}\right)^{h}$} & Subsite 1 & $0.50,1.04$ & $90 \%$ & $0.28,0.28$ & \multirow{2}{*}{$80 \mathrm{~K}$} & \multirow{2}{*}{ S28 } \\
\hline & Subsite 2 & $0.57,2.39$ & $10 \%$ & $0.30,0.30$ & & \\
\hline
\end{tabular}

${ }^{a}$ All values reported in $\mathrm{mm} \mathrm{s}^{-1} \cdot{ }^{b}$ All data collected in frozen 2-MeTHF solutions with zero magnetic field unless noted otherwise. ${ }^{c}$ Data collected as a solid dispersed in boron nitride. ${ }^{d}$ Data collected in presence of $50 \mathrm{mT}$ parallel field. ${ }^{e}$ Generated photolysis of $2\left({ }^{57} \mathbf{F e}\right) .{ }^{f}$ Generated thermolysis of $2\left({ }^{57} \mathbf{F e}\right) .{ }^{8} \mathrm{Generated}$ HAT reaction with $3\left({ }^{57} \mathbf{F e}\right) .{ }^{h} \mathrm{Generated}$ addition of LiOH to $1^{0 x}\left({ }^{57} \mathrm{Fe}\right)$. 


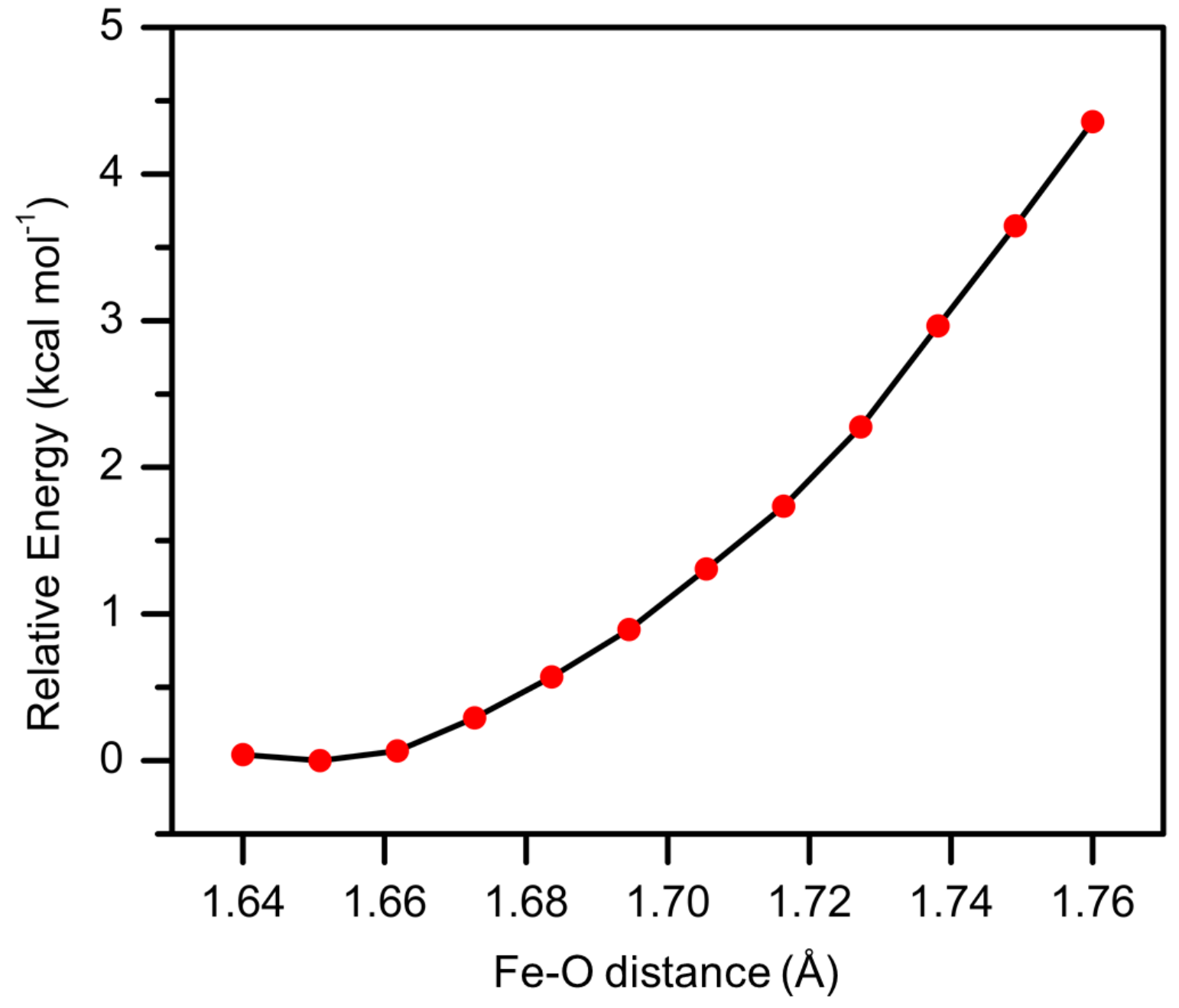

Figure S29. Energy scan of different $\mathrm{Fe}-\mathrm{O}$ bond lengths for 3. The $\mathrm{Fe}-\mathrm{O}$ bond distance was stepped in $0.011 \AA$ increments, and at each point the geometry was optimized while holding the $\mathrm{Fe}-\mathrm{O}$ bond fixed. Geometry scan was performed at the B3LYP/6-31g level of theory. 
Table S9. Comparison of experimental and calculated bond metrics for 1, 2, 3, 4, $1^{\mathrm{ox}}$, and $1^{\text {ox }}$ (THF)

\begin{tabular}{|c|c|c|c|c|c|c|c|c|c|c|c|}
\hline & \multicolumn{3}{|c|}{1} & \multicolumn{2}{|c|}{$2^{b}$} & \multicolumn{2}{|c|}{3} & \multicolumn{2}{|c|}{4} & \multirow{2}{*}{$\begin{array}{c}\mathbf{1}^{\mathbf{o x}} \\
D F T\end{array}$} & \multirow{2}{*}{$\frac{\mathbf{1}^{\mathbf{0 x}}(\mathbf{T H F})}{D F T}$} \\
\hline & $X R D^{a}$ & EXAFS & $D F T$ & EXAFS & $D F T$ & EXAFS & $D F T^{c}$ & EXAFS & $D F T$ & & \\
\hline $\mathrm{Fe}-\mathrm{S} 1$ & $2.371(2)$ & - & 2.36 & - & 2.38 & - & 2.36 & - & 2.40 & 2.30 & 2.34 \\
\hline $\mathrm{Fe}-\mathrm{S} 2$ & $2.410(2)$ & - & 2.37 & - & 2.30 & - & 2.37 & - & 2.44 & 2.30 & 2.34 \\
\hline $\mathrm{Fe}-\mathrm{N} 1$ & $2.193(5)$ & - & 2.17 & - & 2.35 & - & 2.20 & - & 2.33 & 2.12 & 2.25 \\
\hline $\mathrm{Fe}-\mathrm{N} 2$ & $2.279(5$ & - & 2.26 & - & 2.34 & - & 2.09 & - & 2.28 & 2.22 & 2.25 \\
\hline $\mathrm{Fe}-\mathrm{N} 3$ & $2.287(5)$ & - & 2.27 & - & 2.38 & - & 2.10 & - & 2.26 & 2.24 & 2.34 \\
\hline $\mathrm{Fe}-\mathrm{O}$ & - & - & - & 1.93 & 1.90 & 1.69 & 1.70 & 1.91 & 1.89 & - & 2.22 \\
\hline $\mathrm{Fe}-\mathrm{N}$ avg & 2.25 & 2.28 & 2.23 & 2.17 & 2.36 & 2.22 & 2.13 & 2.25 & 2.29 & 2.20 & 2.28 \\
\hline $\mathrm{Fe}-\mathrm{S}$ avg & 2.39 & 2.50 & 2.37 & 2.68 & 2.34 & 2.32 & 2.36 & 2.39 & 2.42 & 2.30 & 2.34 \\
\hline
\end{tabular}

${ }^{a}$ Bond metrics obtained from reference $3 .{ }^{b}$ Bond lengths averaged from each half of dimer. ${ }^{c}$ Optimized with a constrained $\mathrm{Fe}-\mathrm{O}$ distance of $1.70 \AA$ A using B3LYP/6-311G* functional/basis set combination.

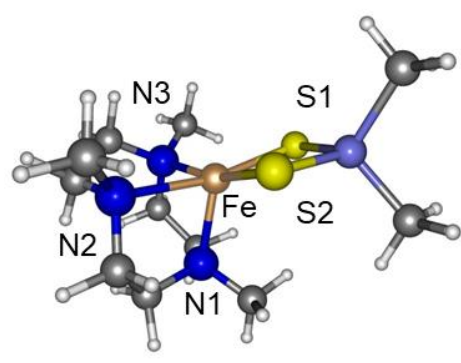

1

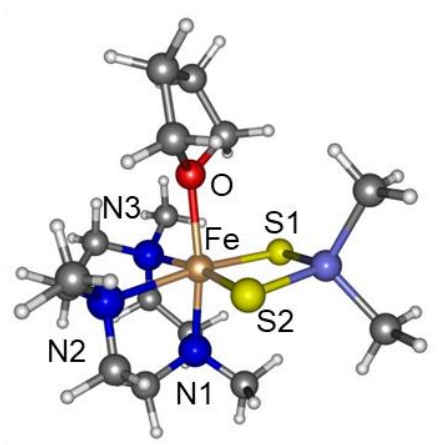

$10 x(T H F)$

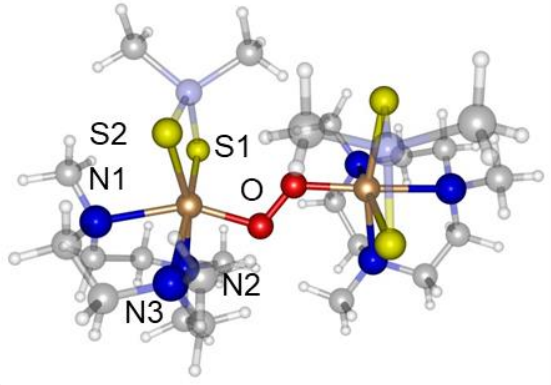

2

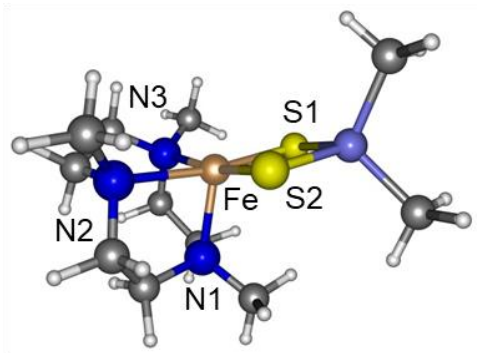

$1^{\mathrm{ox}}$

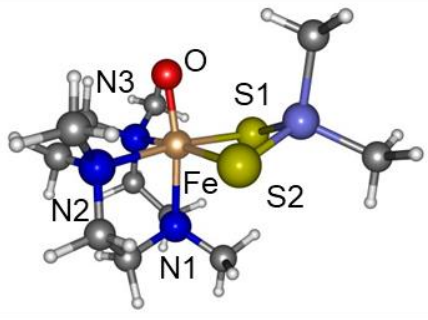

3

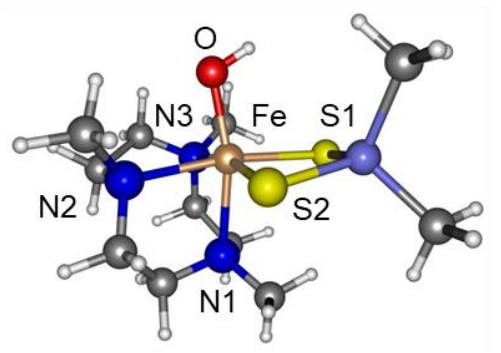

4

Figure S30. DFT-optimized structures of $1,2,3,4,1^{0 x}$, and $1^{\text {ox }}$ (THF). 


\section{Coordinates from DFT geometry optimizations}

\section{Geometry-optimized coordinates for ${ }^{5}\left[\mathrm{Fe}^{\mathrm{II}}\left(\mathrm{Me}_{3} \mathrm{TACN}\right)\left(\mathrm{S}_{2} \mathrm{SiMe}_{2}\right)\right]$}

\begin{tabular}{|c|c|c|c|}
\hline & & 1.40013011404759 & 2.90800936721588 \\
\hline & & 1.78659804724841 & 0.59313433794229 \\
\hline & 1.46776957250104 & 3.63782630970879 & 3.44025628778802 \\
\hline & 1.45388373088660 & 3.80660321501722 & 1.29591982830418 \\
\hline & 4.23038823839661 & 1.00869169805522 & 3.13477118784385 \\
\hline & 2.07039907037192 & -0.84913196798038 & 2.71948952494896 \\
\hline & 2.12391739001163 & 0.79714673989310 & 5.09215049186512 \\
\hline & 2.86474587179726 & 4.91106528725249 & 0.69959796947818 \\
\hline & -0.18505951344629 & 4.53048461872762 & \\
\hline & 4.98879289662867 & 2.15806347903575 & 2.59527510981790 \\
\hline & 4.44361375605308 & -0.19307766611006 & 2.28621133132900 \\
\hline & 4.57201666656666 & & \\
\hline & & & 455794492 \\
\hline & 1.32050700753592 & -1.34580 & 1.54393987096894 \\
\hline & 1.37778363122757 & -1.289 & \\
\hline & & & \\
\hline & 1.074 & & 39077 \\
\hline & 3.465 & & \\
\hline & 3.83838 & 4.53 & 1.05478285391946 \\
\hline & 2.89113585101081 & & -0.40463586417354 \\
\hline & 2.73 & & \\
\hline & -0.32845564624472 & 5.55003598641120 & 1.10058195105453 \\
\hline & -0.20576993169729 & 4.58694733323289 & -0.40466514417977 \\
\hline & -1.0311 & 25427 & 729809 \\
\hline & 6.08102730195708 & 396254061 & 2.61849213193630 \\
\hline & 4.66878223368903 & & \\
\hline & 4.76 & & 3712 \\
\hline & 4.25579339632620 & 0.12331880031804 & 1.24568456895168 \\
\hline & & -0.54886845762 & \\
\hline & 4.75 & $-0.2 \mathrm{~S}-\mathrm{s}-\mathrm{x}$ & 25363551 \\
\hline & 5.51742121335667 & 1.29516615335718 & 4.82207402623214 \\
\hline & 3.76652262608894 & & \\
\hline & 3.58 & -2.1 & 882836 \\
\hline & 0.30891413182510 & -0.91327889286784 & 1.54783765139909 \\
\hline & & & \\
\hline & & -2.4 & 27751 \\
\hline & 0.32966877345182 & -0.95396008296012 & 3.87110460753179 \\
\hline & & & \\
\hline & 3.01069135738397 & -1.11648603669163 & 5.38340061257265 \\
\hline & & & 6.08793751818698 \\
\hline & & & \\
\hline & 0.08773513723945 & 1.08272478115639 & 5.57825545243513 \\
\hline & & 1.17055993490695 & 6.99153601276155 \\
\hline & & 2.40057560086061 & 5.44121858908950 \\
\hline & 3.69791846372910 & 1.02026179003845 & 6.54570167709041 \\
\hline
\end{tabular}




\section{Geometry-optimized coordinates for $\mathrm{BS}(5,5) \mathrm{Fe}_{2}\left(\mathrm{O}_{2}\right)\left(\mathrm{Me}_{3} \mathrm{TACN}\right)_{2}\left(\mathrm{~S}_{2} \mathrm{SiMe}_{2}\right)_{2}$}

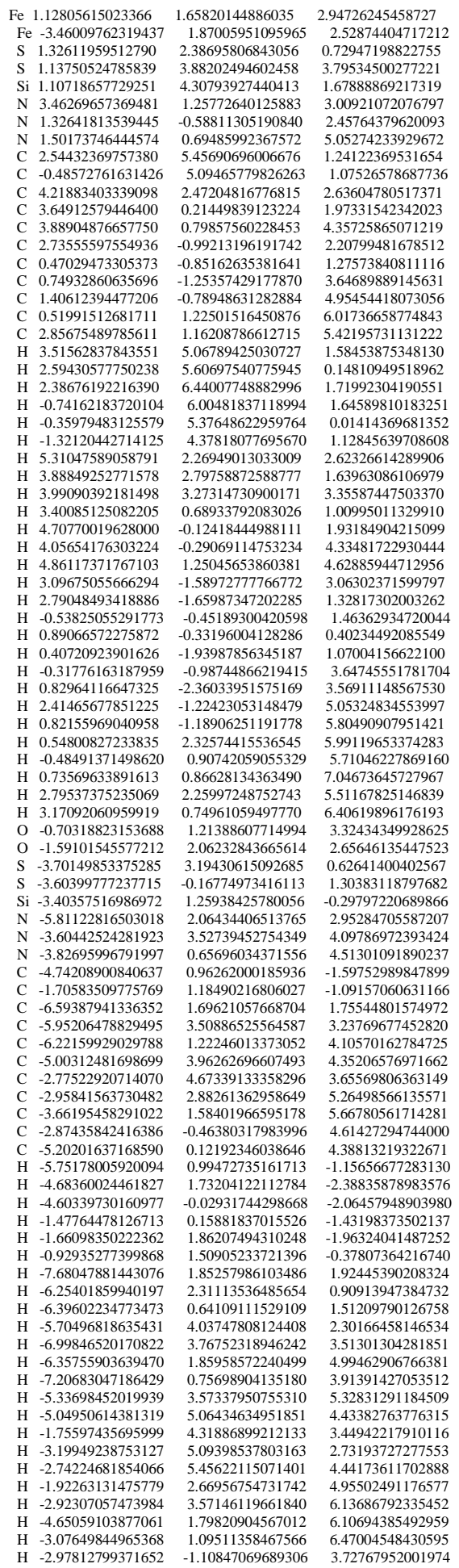




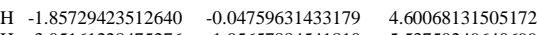

$\begin{array}{llll}\text { H } & -3.05161228475276 & -1.05657884541810 & 5.53750249640699\end{array}$

$\begin{array}{llll}\text { H } & -5.18394795172063 & -0.58483685075184 & 3.54150366219529\end{array}$

H $\quad-5.49807092433973 \quad-0.43805353277044 \quad 5.30271673628658$

\section{Geometry-optimized coordinates for ${ }^{6}\left[\mathrm{Fe}^{\mathrm{III}}\left(\mathrm{Me}_{3} \mathrm{TACN}\right)\left(\mathrm{S}_{2} \mathrm{SiMe}_{2}\right)\right]^{+}$}

\begin{tabular}{|c|c|c|c|}
\hline & 2.13207017222367 & 1.40133734490138 & 2.90819001345317 \\
\hline & 1.88392786741448 & 1.75961222821756 & 0.65038843269163 \\
\hline & & & 3.45626906561733 \\
\hline & 1.57545460894900 & 3.80440814098896 & 1.30575395611826 \\
\hline & 4.21813602835479 & 1.06263301542846 & 3.11028246738723 \\
\hline & 2.03415456887120 & -0.81228051969935 & 2.72529108238074 \\
\hline $\mathrm{N}$ & 2.09187563215252 & 0.79655478894510 & 5.06313541083751 \\
\hline & 2.90559793307102 & 4.93903857208411 & 0.62948499584077 \\
\hline & -0.15948231616807 & 4.35898513828581 & 0.86412291891510 \\
\hline $\mathrm{C}$ & 5.03253126601150 & 2.18406350488464 & 2.57083695792398 \\
\hline & & -0.16517925318170 & \\
\hline $\mathrm{C}$ & 4.54405269539641 & & 4.56407602431580 \\
\hline $\mathrm{C}$ & 3.45885552488466 & -1.28897414534359 & 5788406 \\
\hline & & & \\
\hline $\mathrm{C}$ & 1.34607349125999 & -1.289847 & 25820 \\
\hline & 1.98618212733551 & -0.6898896 & 22379 \\
\hline & & & \\
\hline $\mathrm{C}$ & & & \\
\hline & 3.91378304 & & 38576 \\
\hline & & & \\
\hline $\mathrm{H}$ & 2.7534 & 5.96 & 17049 \\
\hline & & & 77610 \\
\hline & -0.27914571288753 & & \\
\hline $\mathrm{H}$ & -0.91113788767294 & 3.66843908946682 & 1.28085835370147 \\
\hline & 6.10 & 873 & 9787 \\
\hline & 4.74712352835164 & 2.365008 & 286713 \\
\hline $\mathrm{H}$ & & & 333470 \\
\hline & & & 79004 \\
\hline & & -0.5 & 48740 \\
\hline $\mathrm{H}$ & & -0.241 & 706632 \\
\hline & & & 40737 \\
\hline & 3.736 & -1.72 & 92387 \\
\hline $\mathrm{H}$ & & & 4293 \\
\hline & & & 6002 \\
\hline & & 147 & 26715 \\
\hline $\mathrm{H}$ & & & 00820 \\
\hline & 020 & -0.97064 & 94632 \\
\hline & 1.36159436887077 & -2.39536122818217 & 4.01098924851409 \\
\hline & & -1.10800652558914 & 5.37551521908783 \\
\hline & & & \\
\hline & 1.06154860919202 & 2.52968982837494 & 5.74567303367728 \\
\hline & & & 5.46771398229528 \\
\hline & & & \\
\hline & 3.37049162698912 & 2.40709551620402 & 5.48807282356782 \\
\hline & 3.64890667884308 & 0.98564331120579 & 6.53140234416170 \\
\hline
\end{tabular}




\section{Geometry-optimized coordinates for ${ }^{6}\left[\mathrm{Fe}^{\mathrm{III}}(\mathrm{THF})\left(\mathrm{Me}_{3} \mathrm{TACN}\right)\left(\mathrm{S}_{2} \mathrm{SiMe}_{2}\right)\right]^{+}$}

\begin{tabular}{|c|c|c|c|}
\hline & & 1.45252168517312 & \\
\hline & 2.32525590698340 & 2.10878500162560 & 0.51177997679481 \\
\hline & 1.91550138201525 & 3.65795035845792 & 3.49126561202803 \\
\hline & 2.02271961463422 & 4.07657760157909 & 1.37269616093519 \\
\hline & 4.24132230398817 & 1.12869862581990 & 3.03422075209768 \\
\hline & 2.15145416423916 & -0.78514427242640 & \\
\hline & 2.09875021919601 & & \\
\hline & 3.46769609416930 & 5.20954943670367 & 0.97338145838205 \\
\hline & 0.42284476686759 & 4.86487175458742 & \\
\hline & 5.07970558117378 & & \\
\hline & 4.51873385313654 & -0.04588575713501 & 2.15904472723501 \\
\hline & & & \\
\hline & 3.59045000298739 & -1.21268040600295 & \\
\hline & 1.46400843461663 & -1.28265399561395 & 60392427976 \\
\hline & & & \\
\hline & & & 61998 \\
\hline & 1.06931579811153 & & 74192 \\
\hline & & & \\
\hline & & & \\
\hline & 3.52014136011472 & & 87409 \\
\hline & & & \\
\hline & 0.36643 & & \\
\hline & 0.403390401 & & \\
\hline & & & \\
\hline & 6.15130969808103 & & 539006973 \\
\hline & 4.84 & & \\
\hline & 4.8562 & & \\
\hline & & & \\
\hline & 5.57 & $-0.3 t$ & 15275 \\
\hline & & & \\
\hline & & & \\
\hline & 3.85 & & 76493 \\
\hline & 3.72343842418360 & & 1.7155 \\
\hline & & & \\
\hline & 1.89 & & \\
\hline & 1.57333479176734 & -2.38 & 88878737 \\
\hline & & & \\
\hline & 1.46 & & \\
\hline & 3.0401546 & -1.15 & 5.19867132391729 \\
\hline & & & \\
\hline & & & \\
\hline & 0.1041 & 089548 & 5.67838954594041 \\
\hline & & & \\
\hline & & & \\
\hline & 3.64705495 & 710350561 & 41030 \\
\hline & & & \\
\hline & & & \\
\hline & -0.80049018822114 & 1.24909542969695 & 1.08284493697652 \\
\hline & & & \\
\hline & & & \\
\hline & -0.81256693695119 & 56465973 & 0.67547126022303 \\
\hline & & & \\
\hline & -2.196205512075 & -0.36307573443171 & \\
\hline & -2.92642801150735 & 1.03521767308086 & 0.62410178230437 \\
\hline & & & \\
\hline & -3.23912258508148 & 2.18997495318169 & 2.71411115111261 \\
\hline & & 3.00351566686244 & \\
\hline & & 1.64545707394765 & 4.29456678849462 \\
\hline
\end{tabular}




\section{Geometry-optimized coordinates for ${ }^{3}\left[\mathrm{Fe}^{\mathrm{IV}}(\mathrm{O})\left(\mathrm{Me}_{3} \mathrm{TACN}\right)\left(\mathrm{S}_{2} \mathrm{SiMe}_{2}\right)\right]$}

\begin{tabular}{|c|c|c|c|}
\hline & & & \\
\hline & & & 2.88750221981010 \\
\hline & 2.29487320804713 & 1.84934346086306 & 0.64828708344723 \\
\hline & & & \\
\hline & & & 27177232952206 \\
\hline & 4.19070474519781 & 1.00507149095724 & .15343143834147 \\
\hline & & & \\
\hline & 2.05844440141994 & & \\
\hline & 2.76101899286030 & 5.16299378694259 & 0.40561895248150 \\
\hline & & 4.14704769299031 & \\
\hline & 5.06205513736698 & 2.09826444754215 & 2.65860188812579 \\
\hline & 4.44538673664890 & 3274770 & 12916 \\
\hline & & & \\
\hline & & & 59215 \\
\hline & 1.31 & & \\
\hline & & & \\
\hline & & & \\
\hline & 0.97 & & \\
\hline & & & \\
\hline & & & \\
\hline & 2.52 & & \\
\hline & & & \\
\hline & -0.35 & 1274 & 55681 \\
\hline & -0.3 & & \\
\hline & -0.63 & & \\
\hline & 6.110 & & \\
\hline & & & \\
\hline & 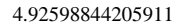 & & \\
\hline & & & \\
\hline & & & \\
\hline & & & \\
\hline & & & \\
\hline & & & \\
\hline & & & 064 \\
\hline & & & \\
\hline & & & \\
\hline & 1.13197303742708 & -2.2437 & 1.45323013228795 \\
\hline & & & \\
\hline & & & \\
\hline & 2.83119159821085 & -1.07624708882240 & 5.36891743122888 \\
\hline & & & \\
\hline & & & \\
\hline & 0.02212894454573 & 1.24364278111922 & 5.27524383293252 \\
\hline & & & \\
\hline & & & \\
\hline & $1441066 / 045$ & 0.95142672696459 & 6.52243102414390 \\
\hline
\end{tabular}




\section{Geometry-optimized coordinates for ${ }^{6}\left[\mathrm{Fe}^{\mathrm{III}}(\mathrm{OH})\left(\mathrm{Me}_{3} \mathrm{TACN}\right)\left(\mathrm{S}_{2} \mathrm{SiMe}_{2}\right)\right]$}

\begin{tabular}{|c|c|c|c|}
\hline & 1.81784191227024 & 1.37635704273147 & 2.88444031014576 \\
\hline $\mathrm{O}$ & -0.05338240635566 & 1.09785401352714 & 2.96549592863185 \\
\hline & 1.98984847786614 & 1.87344519471114 & 0.54141849800212 \\
\hline & 1.98645662371784 & 3.75979869078005 & 3.39522107265457 \\
\hline & 1.74577681514802 & 3.89481207992152 & 1.26695894267013 \\
\hline $\mathrm{N}$ & 4.12290346215378 & 1.07855738803614 & 3.08889498896967 \\
\hline $\mathrm{N}$ & 2.06735499356203 & -0.88364516672120 & 2.70873184835086 \\
\hline $\mathrm{N}$ & 2.03808934123183 & 0.78326385612247 & 5.05032488222555 \\
\hline $\mathrm{C}$ & 3.04129909534653 & 5.03275816266954 & 0.50284580508362 \\
\hline $\mathrm{C}$ & 0.01694564888070 & 4.51436627201457 & 0.83876872196188 \\
\hline $\mathrm{C}$ & 4.91495321285726 & 2.20998102199064 & 2.55276124211917 \\
\hline $\mathrm{C}$ & 4.39416254978282 & -0.12549479484746 & 2.25952685761680 \\
\hline $\mathrm{C}$ & 4.47146990689326 & 0.85865427854602 & 4.52787581255989 \\
\hline $\mathrm{C}$ & 3.49718648897254 & -1.29873928381050 & 2.64920042084839 \\
\hline $\mathrm{C}$ & 1.33495809370543 & -1.358938 & 19134452 \\
\hline $\mathrm{C}$ & 1.37990435531755 & -1.35583190803609 & 6365231 \\
\hline $\mathrm{C}$ & 1.96908095492665 & -0.70445961635174 & 5.18865349728228 \\
\hline $\mathrm{C}$ & 0.94084145790751 & 1.41499394697036 & 5.81835817353415 \\
\hline $\mathrm{C}$ & 3.35671664732146 & 1.32477054517048 & 5.46638882498663 \\
\hline $\mathrm{H}$ & 4.06342069998660 & 4.68269557072817 & 0.72437834646403 \\
\hline $\mathrm{H}$ & 2.91664734364216 & 5.07342345792583 & -0.59477218544394 \\
\hline $\mathrm{H}$ & 2.93140191981713 & 6.05680446576749 & 0.90316178328779 \\
\hline $\mathrm{H}$ & -0.13477832552379 & 5.53638873062596 & 1.23050840229391 \\
\hline $\mathrm{H}$ & -0.13502337795021 & 4.53448048929010 & -0.25571184995912 \\
\hline $\mathrm{H}$ & 5841913 & 8816 & 5864212 \\
\hline $\mathrm{H}$ & 5.99744608753491 & 1.9727 & 2.5772478867 \\
\hline $\mathrm{H}$ & 4.60130667198739 & 2.403 & 1.51 \\
\hline $\mathrm{H}$ & 4.71387544051084 & 3.10757380207129 & 3.15355477151598 \\
\hline $\mathrm{H}$ & 4.19700706850132 & 0.16620202971314 & 1.21430875045172 \\
\hline $\mathrm{H}$ & 5.45917806081753 & -0.42759699607351 & 2.33740255218073 \\
\hline $\mathrm{H}$ & 4.69160594994552 & -0.20770199103260 & 4.68858609172465 \\
\hline $\mathrm{H}$ & 5.39905000904786 & 1.40247426926984 & 4.77806329756370 \\
\hline $\mathrm{H}$ & 3.79774179841932 & -1.70814327780512 & 3.62588107226493 \\
\hline $\mathrm{H}$ & 3.62866262331463 & -2.11656858599192 & 1.91855848288753 \\
\hline $\mathrm{H}$ & 0.32242 & 458192391 & 1.53551468543362 \\
\hline $\mathrm{H}$ & 1.84953587765207 & -1.00632348297602 & 0.60760452741752 \\
\hline $\mathrm{H}$ & 1.28185798090222 & -2.46573721491826 & 1.50096905303607 \\
\hline $\mathrm{H}$ & 0.32561004765112 & -1.05785037287677 & 3.82807198447804 \\
\hline $\mathrm{H}$ & 1.43988114182606 & -2.46009928856138 & 4.02503483374560 \\
\hline $\mathrm{H}$ & 2.97816124814340 & -1.09249622699648 & 5.39457739280706 \\
\hline $\mathrm{H}$ & 1.35030885244214 & -0.97289618263953 & 6.06329951762069 \\
\hline $\mathrm{H}$ & 0.98122335874103 & 2.50624603552841 & 5.67804400062441 \\
\hline $\mathrm{H}$ & -0.01603513306687 & 1.04956277993717 & 5.41877992586284 \\
\hline $\mathrm{H}$ & 1.02732365051655 & 1.17178555767558 & 6.89602195978739 \\
\hline $\mathrm{H}$ & 3.27516966065356 & 2.42279582471155 & 5.43196597422631 \\
\hline $\mathrm{H}$ & 3.59597177041446 & 1.02681657196775 & 6.50754474722542 \\
\hline $\mathrm{H}$ & -0.51331332913378 & 1.26535419814246 & 2.11910477296977 \\
\hline
\end{tabular}




\section{References}

(1) Gütlich, P.; Bill, E.; Trautwein, A., Mössbauer spectroscopy and transition metal chemistry: fundamentals and applications. Updated ed.; Springer-Verlag: Berlin, 2011.

(2) McDonald, A. R.; Que, L. High-valent nonheme iron-oxo complexes: Synthesis, structure, and spectroscopy. Coord. Chem. Rev. 2013, 257, 414-428.

(3) Komuro, T.; Matsuo, T.; Kawaguchi, H.; Tatsumi, K. Coordination Chemistry of Silanedithiolato Ligands Derived from Cyclotrisilathiane: Synthesis and Structures of Complexes of Iron(II), Cobalt(II), Palladium(II), Copper(I), and Silver(I). Inorg. Chem. 2003, 42, 5340-5347. 